\title{
Cholinergic Anti-inflammatory Pathway: An insight into Inflammatory Diseases Treatment with Chinese Herbal Medicine
}

\author{
An Yuan ${ }^{1}$, Ming Gao ${ }^{1}$, Baojun Wang $^{1}$, and Nan Zeng ${ }^{1}$ \\ ${ }^{1}$ Chengdu University of Traditional Chinese Medicine
}

October 21, 2020

\begin{abstract}
Given the significant role of inflammation during various diseases, the anti-inflammatory mechanism of Chinese herbal medicine through the cholinergic anti-inflammatory pathway (CAP) is being developed from basic research to clinical application in inflammatory diseases. CAP is a neuro-immunomodulatory pathway that exerts a more rapid and efficient response to systemic inflammatory responses, providing new directions for the research and treatment of inflammatory diseases. Chinese herbal medicine prescriptions, single herb, extracts, and components exhibited significant anti-inflammatory and immunomodulatory effects through CAP for the treatment of sepsis, acute lung injury, COVID-19, Alzheimer's disease, etc. The present article comprehensively and systematically reviewed the anti-inflammatory mechanisms of CAP. Simultaneously, its related pathways such as JAK2/STAT3 and NF- $x$ B were listed. The role of CAP in various inflammatory diseases and Chinese herbal medicine mechanism through CAP was also summarized. The purpose of this article looks forward to providing new targets and perspective for treatment of inflammatory diseases.
\end{abstract}

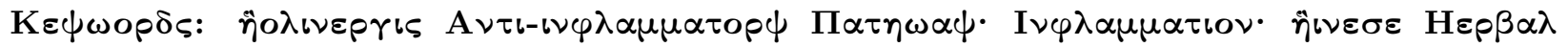

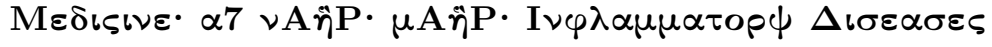

\section{Abbreviation}

ACh, Acetylcholine; AChE, Acetylcholinesterase; AD, Alzheimer's disease; Akt, Protein-serine-threonine kinase; ALI, Acute lung injury; CAP, Cholinergic anti-inflammatory pathway; ChAT, Choline acetyltransferase; CHM, Chinese herbal medicine; COVID-19, Coronavirus disease 2019; FLS, Fibroblast-like synoviocytes; HMGB1, High mobility group box 1; IC50, Half-maximal inhibitory concentration; IKK $\beta$, Inhibitor of nuclear factor kappa-B kinase; IL-1 $\beta$, Interleukin-1 $\beta$. IL-6, Interleukin-6; JAK2, Janus kinase 2; LPS, Lipopolysaccharide; mAChR, Muscarinic acetylcholine receptor; MAPK, Mitogen-activated protein kinase; NE, Norepinephrine; NF-xB, Nuclear factor kappa-B; NTS, Nucleus tractus solitarius; PI3K, Phosphatidylinositol-3- kinase; POI, Postoperative ileus; RA, Rheumatoid arthritis; SOCS3, suppressor of cytokine signaling 3; STAT3, Signal transducer and activator of transcription 3; T2DM, Type 2 diabetes; TBI, Traumatic brain injury; TLR4, Toll-like receptor 4; TNF- $\alpha$, Tumor necrosis factor- $\alpha \cdot$ vAChT, Vesicle acetylcholine transporter; VD, Vascular dementia; $\alpha 7 \mathrm{nAChR}$, Nicotinic acetylcholine receptor $\alpha 7$.

\section{1 | INTRODUCTION}

Infection or tissue damage can trigger the body's innate immune activation and protective inflammation responses. For an organism that has been invaded by viruses, bacteria, etc., an appropriate inflammatory response is a favorable regulation to prevent the most threat of disease. The lack or excessive inflammation is not only a part of many diseases, but also an important mechanism of these diseases, such as sepsis, acute lung injury (ALI), rheumatoid arthritis (RA), atherosclerosis, diabetes, hemorrhagic shock, pancreatitis, 
Alzheimer's disease (AD), multiple sclerosis, cardiovascular and cerebrovascular diseases, and even cancer (Tracey, 2002). According to the Coronavirus disease 2019 (COVID-19) outbroke, the patients with the highest morbidity and mortality after severe acute respiratory syndrome coronavirus 2 (SARS-CoV-2) infection mainly developed into hyperinflammatory syndromes such as acute respiratory distress syndrome and septic shock. That is, the immune system was triggered by the cytokine storm to attack the body violently, and it also caused serious damage to the body because of excessive inflammation. Excessive inflammation is a serious injury to the body.

Clinically, inflammatory diseases are treated by drug treatment, acupuncture, meditation, hypnosis, relaxation therapy, and physical exercise improvement, along with increased vagal activities and reduced inflammatory cytokine levels. In addition to these treatments by humoral regulation as we know, there are other ways to do it? The nerve and immune system do not exist completely independently, and they regulate the balance of the body through neurotransmitters and cytokines. The nervous system integrates inflammatory response information, signals are sent out to regulate inflammation mainly through the vagus nerve, the release of activated macrophages and cytokines is inhibited, and inflammation is rapidly regulated. This pathway is known as the "cholinergic anti-inflammatory pathway (CAP)" (Borovikova et al., 2000). In this pathway, the central nervous system receives the body's immune stimulation information and projects it to the vagal nucleus, activating the efferent fibers of the vagus nerve. Acetylcholine $(\mathrm{ACh})$ is released from peripheral nerve endings. After ACh binds to receptors such as nicotinic acetylcholine receptor $\alpha 7$ ( $\alpha 7 \mathrm{nAChR})$, it connects Janus kinase 2/ Signal transducer and activator of transcription 3 (JAK2/STAT3) and nuclear factor kappa-B (NF- $x \mathrm{~B})$, inhibits $\mathrm{NF}-\varkappa \mathrm{B}$ activation, prevents $\mathrm{T}$ cell differentiation, and inhibits neutrophils and monocytes Cell lethality, thereby inhibiting the inflammatory response. It's a physiological mechanism that inhibits cytokine production and minimizes tissue damage during inflammation. Compared with the humoral pathway, this pathway is characterized by more sensitive induction and faster response. Overall, scholars have two key research points on this pathway. On the one hand, the focus is on studying the mechanism of CAP (including related pathways, target sites, and the relationship between diseases). On the other hand, the focus is on the mechanism of drugs through CAP to treat inflammatory diseases. In future research, we will explore how the brain regulates the body's inflammation, which pathways are regulated by drugs, and which ways dominate.

With the widespread application of Chinese herbal medicine (CHM) in anti-inflammatory immunity has attracted more attention. CHM is a complex of natural pharmaceutical ingredients, which contains a variety of anti-inflammatory ingredients such as alkaloids, glycosides, polysaccharides, etc. The combination of various CHM in the traditional Chinese medicine prescriptions can achieve the effect of increasing efficacy and reducing toxicity. With the gradual increase in researches, the anti-inflammatory mechanism of CHM is not only related to NF- $\varkappa \mathrm{B}$, JAK2/STAT3, MAPK pathway in traditional sense, but also related to CAP, especially in sepsis, Alzheimer's disease, arthritis, cardiovascular disease, and other diseases. This review summarizes and analyzes CAP key parts, focusing on the relationship between CAP and inflammatory diseases, as well as mechanism research progress of CHM prescriptions, single herb, extracts and components on these inflammatory disease through CAP (analytical framework shown in Figure 1). It is expected to provide a reference for the drug treatment of inflammatory diseases, expand the treatment of CAP-related diseases, and provide new targets, ideas, and theoretical basis for the study of immunomodulation.

\section{2 | RESEARCH OVERVIEW ON CAP MECHANISM}

Among the key parts of CAP, the effects of vagus nerve and $\alpha 7 \mathrm{nAChR}$ are relatively identified. In CAP, muscarinic receptors $(\mathrm{mAChR})$, microRNAs (miRNAs), $\beta 2$ adrenergic receptors, spleen also play a role in it (Figure 2). 


\section{1 | Vagus nerve}

Anti-inflammatory effect of CAP depends on the integrity of the vagus nerve. Vagus nerve is the connector of brain and immune system (spleen, liver, etc.). Inflammatory cytokines released by macrophages, dendritic cells, and immune cells could locally activate vagus nerve fibers. Signal is transmitted to nucleus tractus solitarius (NTS) in the medulla oblongata (Tracey, 2009). NTS takes the integrated information to make a decision and project it into efferent vagus nerve in the dorsal motor nucleus, prompting ACh to release at the target organ and activating cholinergic receptors in macrophages, such as $\alpha 7 \mathrm{nAChR}$, thereby inhibiting the generation of inflammatory cytokines (Ulloa, 2005). Vagus nerve regulation on TNF is one of the most deeply studied anti-inflammatory mechanisms, and it also reduces the levels of IL-1 $\beta$, IL-6, and high mobility group box 1 (HMGB1). Parasympathetic nerves are involved in controlling the inflammatory responses, while skin and skeletal muscles can also exhibit cholinergic anti-inflammatory regulation without vagal innervation. Studies have indicated that vagus nerve is not a proprietary attribute of inflammatory cholinergic regulation (Pereira \& Leite, 2016). Thus, the regulation of other parts of CAP needs further study.

\section{2 | Nicotinic receptor}

Cholinergic receptors are nicotinic receptors (nAChR) and $\mathrm{mAChR}$, the anti-inflammatory effects of cholinergic transmitters are mainly mediated by $\mathrm{nAChR}$. $\mathrm{nAChR}$ is a member of four transmembrane domains superfamilies of neurotransmitter-gated ion channels. These receptors play a central role in regulating synaptic nerve transmission and basic intracellular signaling, and controlling the viability of neuronal and the structure of synaptic. Moreover, $\alpha 7 \mathrm{nAChR}$ is the closest receptor to inflammation and has a high affinity for $\alpha$-silver snake toxin. It is a homopentamer that composed of five $\alpha 7$ subunits and is extensively distributed among macrophages, endothelial cells, lymphocytes, glial cells, and intestinal epithelial cells, etc. Besides, $\alpha 7 \mathrm{nAChR}$ is associated with obesity, diabetes, $\mathrm{AD}$, arthritis, asthma, atherosclerosis, cancer, and psoriasis (Bencherif, Lippiello, Lucas, \& Marrero, 2011). Activation of $\alpha 7 n$ AChR contained in lymphocytes and macrophages can regulate their activation, and macrophages mediate the physiological control of cytokine production by autocrine/paracrine ACh through nAChR (De Rosa, Dionisio, Agriello, Bouzat, \& Esandi Mdel, 2009; Gotti \& Clementi, 2004). Activation of $\alpha 7 \mathrm{nAChR}$ can suppress the release of inflammatory cytokines such as TNF, IL-1 $\beta$, IL-6, IL-8 and HMGB1. ACh is the most direct agonist affecting $\alpha 7 \mathrm{nAChR}$, and related enzymes such as AChE may have potential therapeutic significance. The inhibition of AChE is a key way to treat diseases such as $\mathrm{AD}$ (Y. Jiang, Gao, \& Turdu, 2017). Therefore, $\alpha 7 n A C h R$ and ACh-related enzymes have become important targets for inflammation-related diseases treatment.

\section{$2.3 \mid$ Muscarinic receptors}

The muscarinic receptor ( $\mathrm{mAChR}$ ) is a seven-transmembrane domain $\mathrm{G}$ protein-coupled receptor composed of five different subtypes, namely M1-M5. It can mediate many biological effects, including the regulation of heart rate, glandular secretion, smooth muscle contraction, and central nervous system (Kruse et al., 2014). The role of peripheral $\mathrm{mAChR}$ in inflammation is still controversial. Intravenous injection of $\mathrm{mAChR}$ inhibitor atropine methyl nitrate in endotoxemia rats cannot eliminate the inhibitory effect of vagal nerve stimulation on TNF, nor can it inhibit serum TNF(Pavlov et al., 2006). Another study found that M1 and M5 mAChRs are involved in regulating the production of cytokines (such as IL-6), resulting in the switch regulation of antibody class from IgM to IgG1, up-regulating immune response of protein antigens, but not participating in the initial production response of antibodies (Fujii et al., 2007). However, further validation of central mAChR agonists found that the stimulation of $\mathrm{nAChR}$ and $\mathrm{mAChR}$ significantly reduced the levels of pro-inflammatory cytokines like IL-1 $\beta$, IL-6, macrophage inflammatory protein 2 (MIP-2), and animal mortality in early sepsis. CAP are regulated mainly by stimulating central $\mathrm{mAChR}$ and peripheral 7nAChR (Zabrodskii, Lim, Shekhter, \& Kuzmin, 2012). Especially in central inflammatory diseases, it may be closely related to central $\mathrm{mAChR}$, and the mechanism research between them needs to deepen on $\mathrm{mAChR}$ and central inflammation. 


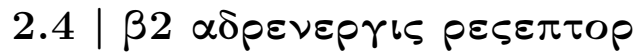

Adrenergic receptors (AR) are a large family of seven transmembrane receptors which respond to catecholamines. Both primary and secondary immune organs are dominated by plenty of sympathetic nerve fibers emitted from the sympathetic postganglionic fibers. When the sympathetic nervous system is excited, the end of the sympathetic nerves that govern each immune system mainly release norepinephrine $(\mathrm{NE})$, which in turn causes a local immune response. Vagus nerve stimulation relies on NE released from splenic sympathetic nerve endings, followed by $\beta 2 \mathrm{AR}$ activation in T lymphocytes (Vida et al., 2011). High concentrations of NE activate lymphocytes, thereby producing ACh in vitro (Rosas-Ballina et al., 2011). These findings indicate that $\beta 2 \mathrm{AR}$ activation imitates CAP. At the same time, $\beta 2 \mathrm{AR}$ activation can also prevent the development of sepsis through additional mechanisms in the innate immune system, such as directly inhibiting cytokine production or increasing bacterial phagocytosis in macrophages (Muthu et al., 2010; Severn, Rapson, Hunter, \& Liew, 1992).

\section{$2.5 \mid$ miRNAs}

miRNAs regulate gene expression in various biological processes. About 5000-10000 miRNAs are expressed in mammalian cells, which regulate more than $60 \%$ of protein-coding genes. miRNAs rapidly stop mRNA translation and adjust specific genes expression, prevent the ability of mRNA translation and degradation more quickly and stronger. It enable CAP to moderate the acute production of inflammatory cytokines, and limit the potentially excessively enthusiastic secondary response while maintaining controlled inflammation monitoring (Ulloa, 2013). miRNAs do not represent an effective mechanism for completely shutting down gene expression. Instead, they usually function as a "regulatory" mechanism that regulates gene expression within range of 1-4 times. This is a typical feature of the cholinergic anti-inflammatory pathway. It uses chemical instability and short life cycle of ACh and miRNAs to quickly regulate inflammation and avoid tissue damage, but maintains baseline expression of infection. Compared with the immunosuppressive effects of glucocorticoids, these mechanisms have biological advantages. Clinical studies have revealed that the function of macrophages in children with intestinal failure is excessively activated. miRNA-124 directly targets the 3' untranslated region of STAT3 and AChE mRNA, inhibits macrophage activation, reduces IL-6 and TNF- $\alpha$ release, and alleviates abdominal inflammation (Y. T. Xiao, Wang, Lu, Cao, \& Cai, 2016). Nicotinic acid can induce miRNA-124 through $\alpha 7 \mathrm{nAChR}$ to inhibit STAT3 tyrosine phosphorylation and protein expression, and negatively regulate the inflammation caused by Toll-like receptor 4 (TLR4) (Qin, Wang, Su, \& Liu, 2016; Y. Sun et al., 2013). miRNA-124a, miRNA-132 and miRNA-205-5b are also the key mediator of cholinergic anti-inflammatory activity (Q. Li, 2011; F. Liu et al., 2015; W. Zhou, Wang, Li, Li, \& Sang, 2016). At present, there are not many drugs studied from this angle, and it is necessary to further clarify which miRNAs is more closely related to CAP.

\section{6 | Spleen}

Anatomically, spleen is necessary for vagus nerve to control inflammatory response (Huston et al., 2008). Spleen is also the main source of serum TNF in endotoxemia, and TNF enters systemic circulation from splenic vein through liver. Vagus nerve regulates cytokines production through two-stage tandem neurons. Preganglionic neurons are located in the dorsal nucleus of vagus motor. Postganglionic neurons come from the superior mesenteric plexus of the abdominal cavity (Agostoni, Chinnock, De Daly, \& Murray, 1957). Splenic nerve fibers are composed of catecholamine fibers (Klein, Wilson, Dzielak, Yang, \& Viveros, 1982). Similarly, spleen produces ACh, but no ACh nerve fibers have been detected (Nance \& Sanders, 2007), and it is still not completely clear whether spleen is innervated by vagus nerve. Studies have found that reserpine consumes catecholamines to eliminate vagal nerve's inhibition of TNF (Nezhinskaia, Vladykin, \& Sapronov, 2010). After spleen resection, vagal nerve stimulation specifically reduces TNF production from macrophages in the red pulp and marginal area (Rosas-Ballina et al., 2008). And the effect of nicotine on reducing the level of HMGB1 in the blood of sepsis animals is inhibited (X. M. Song et al., 2008). 


\section{3 | RELATIONSHIP BETWEEN CAP AND MAIN RELATED PATHWAYS}

\section{1 | JAK/STAT pathway}

JAK/STAT pathway is involved in inflammation and immune responses with duality. Firstly, JAK/STAT1 is the transcription pathway of HMGB1, that is, LPS induces macrophages to release HMGB1 through the TLR4/IFN- $\beta$ /STAT1 signal axis. Secondly, $\alpha 7 n A C h R$ regulates JAK2/STAT3 after being activated. After vagus nerve stimulation or $\alpha 7 \mathrm{nAChR}$ activation, JAK2 is recruited to $\alpha 7 \mathrm{nAChR}$ to form a heterodimeric complex. By phosphorylating STAT3 to reduce the nuclear translocation of NF- $x \mathrm{~B}$ (de Jonge et al., 2005), STAT3 acts as a dominant-negative inhibitor of NF- $x$ B DNA binding activity and directly inhibits proinflammatory cytokines induction by interacting with NF- $x \mathrm{~B}$ p65 (Yu, Zhang, \& Kone, 2002). STAT3 is not directly connected to pro-inflammatory cytokines production, and attenuated cytokine expression mediated by $\alpha 7 n A C h R$ stimulation is a synergy between NF- $\chi \mathrm{B}$ and JAK/STAT (shown in Figure 2C) (Tasaka et al., 2015). Cholinergic agonists (nicotine and GTS-21) inhibit IL-6-mediated MCP-1 production and ICAM-1 expression through JAK2/STAT3 pathway in a SHP1/2 phosphatase-dependent manner. It is associated with a reduction of JAK2 and STAT3 phosphorylation, STAT3-specific DNA binding, and reduction of suppressor of cytokine signaling 3 (SOCS3, a regulator of the JAK2/STAT3 pathway) levels (Chatterjee, Al-Abed, Sherry, \& Metz, 2009). Especially in the anti-inflammatory and inhibitory cell apoptosis pathways, $\alpha 7 \mathrm{nAChR}$ plays a key role in JAK2/STAT3 and NF- $\chi \mathrm{B}$ (Marrero \& Bencherif, 2009). Normally, activation of $\alpha 7 n A C h R$ and inhibition of JAK2 can attenuate STAT3 phosphorylation to exert subsequent responses, while $\alpha 7 n A C h R$ signaling requires STAT3 protein rather than its tyrosine phosphorylation. Unphosphorylated STAT3 can also compete with an inhibitor of NF- $x \mathrm{~B} \alpha(\mathrm{I} \varkappa \mathrm{B} \alpha)$ to bind NF- $\varkappa \mathrm{B}$ and inhibit TNF transcriptional activation to regulate the innate immune response during infection. However, the STAT3-NF- $\chi \mathrm{B}$ complex may enhance the production of other cytokines (Peña et al., 2010).

\section{$3.2 \mid \mathrm{N} \Phi-\varkappa \mathrm{B} \pi \alpha \tau \eta \omega \alpha \psi$}

NF- $x \mathrm{~B}$ inhibition can reduce inflammation and inhibit macrophages/monocytes to play a key role in innate immune response. While NF- $x \mathrm{~B}$ is activated by microbial components (such as LPS, peptidoglycan, dsRNA, etc.) through TLR. The downstream signaling cascade includes I $\chi$ B kinase (IKK) activation, I $\chi \mathrm{B}$ phosphorylation, NF- $x \mathrm{~B}$ translocation, and subsequent gene transcription. Meanwhile, NF- $x \mathrm{~B}$ is also regulated by JAK2/STAT3, as described in 3.1. $\alpha 7 \mathrm{nAChR}$ activation-mediated CAP prevents NF- $\chi \mathrm{B}$ nuclear translocation in macrophages, while nicotine inhibits IKK phosphorylation and NF- $x \mathrm{~B}$ transcriptional activ-

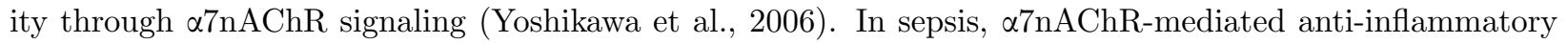
and TLR4-mediated pro-inflammatory pathways are activated, and several pro-inflammatory cytokines are released. The classic anti-inflammatory drug dexamethasone can also inhibit proinflammatory cytokines by up-regulating $\alpha 7 \mathrm{nAChR}$ and $\mathrm{ACh}$, and inhibits TLR4/MyD88/NF- $x \mathrm{~B}$ pathway, thereby inhibiting inflammation. The specific $\alpha 7 \mathrm{nAChR}$ antagonist $\alpha$-bungarotoxin eliminates the effects of dexmedetomidine (Zi et al., 2019).

\section{3 | MAPK pathway}

Mitogen-activated protein kinase (MAPK) signaling pathway includes c-Jun N-terminal kinase (JNK), extracellular regulated protein kinases (ERK), and P38 MAPK. These components can act both independently and synergistically. MAPK activation requires the phosphorylation of its specific amino acid sequence, combined with stimulation of other kinases, translocates to the nucleus and activates the transcription of proinflammatory genes. MAPK is closely related to the downstream NF- $x \mathrm{~B}$ in CAP and plays an important role in inflammation. Regulation of $\alpha 7 \mathrm{nAChR}$ activation by microglia on inflammatory mediators is achieved by inhibiting the P38 and ERK pathways in the MAPK pathway (Lei, 2009). In colitis model, the improvement 
of vagal activity may activate ERK1/2 and NF- $\chi \mathrm{B}$ translocation, and induce the transcription of proinflammatory genes through the interaction of $\alpha 7 \mathrm{nAChR}$ and the peripheral release of $\mathrm{ACh}$ in the inflamed colonic mucosa (P. Sun et al., 2013). K opioid receptor agonists can activate $\alpha 7 \mathrm{nAChR}$ through MAPK-ERK1/2 signaling pathway, regulate CAP, inhibit NF- $x \mathrm{~B}$ expression, reduce inflammation, and postoperative cognitive dysfunction caused by cardiopulmonary bypass (Fan, Duan, \& Sun, 2019). Ligation-induced acute pancreatitis in rats is related to the continuous increase of $\mathrm{M} 3 \mathrm{mAChR}$ expression in a time-dependent manner and is also related to the increase in the activation of stress-activated protein kinase JNK (Samuel, Zaheer, Fisher, \& Zaheer, 2003). JNK is a major negative regulator of intestinal secretion induced by mAChR. $\mathrm{mAChR}$ stimulation increases the phosphorylation of MAPKs and is inhibited by MAPK inhibitors (Khan et al., 2015). Also, activation of $\alpha 7 \mathrm{nAChR}$ (selective agonist PNU282987) significantly reduces apoptosis and intracellular oxidative stress levels and prevents oxidative stress-induced damage by inhibiting the vascular peroxidase-1 in endothelial cells in a JNK signaling pathway-dependent manner (D. J. Li et al., 2014). Consequently, MAPK signaling pathway can also play a role in CAP-mediated inflammation, and its relationship with JAK2/STAT3 and NF- $x \mathrm{~B}$ in CAP is complex.

\section{4 | PI3K/Akt pathway}

PI3K pathway responds to the activation of pro-inflammatory signaling pathway in cells to some extent in the immune defense mechanism (Williams et al., 2004). Activation of $\alpha 7 \mathrm{nAChR}$ results in formation of heterodimeric complexes between $\alpha 7 \mathrm{nAChR}$ protein and JAK2, which can initiate signal transduction mediated by STAT3, followed by PI3K tyrosine phosphorylation and Akt serine phosphorylation (Shaw, Bencherif, \& Marrero, 2002). The relationship between PI3K and TLR4 is still not completely clear and may be bidirectional. On the one hand, TLR4 activates PI3K to limit TNF- $\alpha$ production, and the pharmacological blockade of PI3K leads to enhanced activation of NF- $x \mathrm{~B}$ (Chaurasia et al., 2010). At the same time, it is also possible that PI3K negatively regulates TLR4. PI3K/Akt activation can reduce apoptosis and TLR4 expression, and PI3K inhibitors can increase local inflammation (Ke et al., 2012). Studies have revealed that nicotine inhibits the overexpression of TLR4 by activating the $\alpha 7 \mathrm{nAChR} / \mathrm{PI} 3 \mathrm{~K}$ pathway, and PI3K/Akt plays a negative feedback role in it (T. H. Kim, Kim, \& Lee, 2014).

\section{4 | CAP RELATED DISEASES AND CHINESE HERBAL MEDICINE}

According to existing research reports, diseases related to CAP mainly include sepsis, ALI, AD, cardiovascular and cerebrovascular diseases, arthritis, diabetes, etc. The relevant inflammatory diseases treated by CHM summarized in this review are shown in Figure 3. In connection with these diseases, the external treatment of vagal nerve stimulation such as acupuncture or CHM can be intervened from anti-inflammatory methods. Among them, due to the multicomponent-multitarget-multipathway characteristics of CHM, its anti-inflammatory mechanism may be exerted by multiple pathways. That is, through CAP alone, through non-cholinergic anti-inflammatory pathways, or their common effect. Whether it exerts anti-inflammatory effects through CAP and becomes a potential drug for more diseases has been further developed. Information on the role of CHM through CAP treatment is shown in Table 1.

\section{$4.1 \mid$ ALI}

ALI is a common critical illness in respiratory medicine. It represents one of the earliest complications with the highest incidence after infection or severe trauma. The disease is swift and susceptible to turn into acute respiratory distress syndrome (ARDS). The mortality rate of ARDS is still high at 40\%, ALI and sepsis are important causes of ARDS. In COVID-19, ALI and ARDS are the main pathophysiological changes in critically ill patients. Lung is a place where inflammatory cells activate and accumulate. Endotoxin activates pulmonary vascular endothelial cells and macrophages, releasing large amounts of cytokines and 
inflammatory mediators. Lung tissue is first damaged by the excessive inflammatory response due to excessive inflammation of lung (Wallace \& Donnelly, 2002). $\alpha 7 \mathrm{nAChR}$ is also found on lung epithelial cells, endothelial cells, alveolar macrophages, and neutrophils in ALI mice induced by LPS and live E. coli (Su, Matthay, \& Malik, 2010). During lung infection and inflammation, alveolar macrophages produce MIP-2 and attract neutrophils to migrate into alveoli, and these neutrophil infiltrations also express $\alpha 7 \mathrm{nAChR}$. The release of ACh from vagal nerve endings in distal airways, lung epithelial cells, immune cells, and neuroendocrine cells also produce non-neuronal ACh. Positive feedback between ACh and $\alpha 7 n A C h R$ helps maintain ACh concentration ( $\mathrm{Wu}, \mathrm{Li}, \& \mathrm{Su}, 2014)$. The anti-inflammatory effect of CAP in ALI is closely associated with $\alpha 7 n A C h R$ activation, as well as its downstream NF- $x$ B and JAK/STAT pathways. Moreover, ROS-induced oxidative stress and cell damage are also related to the development of lung injury. $\alpha 7 \mathrm{nAChR}$ protects cells against oxidative stress and thus play a neuroprotective role. After inhibiting $\alpha 7 \mathrm{nAChR}$ gene, the oxidative stress level is significantly enhanced. Therefore, effective regulation of CAP in ALI is beneficial to the control of inflammation.

CHM prescriptions . Liang-Ge-San is published in "Taiping Huimin Heji Ju Fang", which is a famous prescription for clearing away heat and reducing fire. Its anti-inflammatory mechanism is mediated through the NF- $x \mathrm{~B}$, MAPK, JAK-STAT pathways, adjusting the $1 / 2 \mathrm{~T}$ helper cells ratio to regulate immunity. It is commonly used for ALI, pharyngitis and tonsillitis in clinical practice. It significantly inhibited IL-6 and TNF- $\alpha$ production, the degradation and phosphorylation of $\mathrm{I} \chi \mathrm{B} \alpha$, and nuclear translocation of NFxB p65 in RAW 264.7 macrophages stimulated with LPS. After activating $\alpha 7 n A C h R$, selective inhibitor methyllycaconitine (MLA) or $\alpha 7 \mathrm{nAChR}$ siRNA blocked $\alpha 7 \mathrm{nAChR}$, and the inhibitory effects of Liang-GeSan were all weakened (J. S. Liu et al., 2016). Therefore, Liang-Ge-San can prevent ALI induced by LPS through CAP.

Single herb . Scutellariae Radix is a dried root ofScutellaria baicalensis Georgi, which is widely used in acute infections treatment. It has anti-inflammatory, antipyretic, antiendotoxin and other pharmacological effects, which are associated with inhibition of NF- $x$ B pathway. Scutellariae Radix significantly reduced the wet-dry mass ratio of lung tissue in LPS-induced ALI rats, decreased body temperature, lowered serum TNF- $\alpha$ and NO levels, increased ACh levels, and improved lung tissue inflammatory lesions. Its effect on CAP may play an anti-inflammatory effect on indirect transient release promotion, which has nothing to do with biosynthesis (Cui, Meng, Wang, Li, \& Yu, 2012). Coptidis Rhizoma is the dried root of Coptis chinensis Franch., Coptis deltoidei C.Y.Cheng et Hsiao, Coptis teeta Wall. It is commonly used in the treatment of upper respiratory tract infection, cough, jaundice, pneumonia, dysentery, hypertension, etc. It has antiinflammatory, antiviral, and antihypertensive effects, it is also related to the NF- $\varkappa \mathrm{B}$ pathway. Coptidis Rhizoma significantly reduced the wet-dry mass ratio of lung tissue, enhanced lung tissue activity, and reduced serum TNF- $\alpha$ and NO levels, but had no significant effect on ACh and enzyme activity. High-dose Coptidis Rhizoma increased ChAT and ACh levels in brain tissue homogenate and improved inflammatory lesions in lung and brain tissue. Based on the protective mechanism of CAP in ALI rats, the central and peripheral mechanisms of action are different. In central nervous system, Coptidis Rhizoma may reduce the inflammation of brain tissue by indirectly promoting the release of the body, which has nothing to do with biosynthesis. In peripheral tissue, it may play an anti-inflammatory role by increasing the activity of rat lung tissue and promoting synthesis (Cui, 2012).

Extracts . Litchi pit is the dried mature seed of Litchi chinensis Sonn. It is often used clinically for pains such as cold hernia, abdominal pain, testicular swelling, and epigastric pain. Its total flavonoids and total saponins are effective parts, which have the effects of lowering blood sugar, anti-tumor, anti-virus, antiinflammatory, and anti-liver injury. Studies have found that total flavonoids of litchi also has a certain effect on ALI, which decreased the wet-dry weight of lung tissues, IL-1 $\beta, N O, T N F-\alpha$, and NF- $\chi \mathrm{B}$ levels, increased ACh levels and activity of ChAT and AChE in ALI rats. It showed that it could regulate the CAP, inhibit the development of inflammatory response, and protect the damaged lung tissue (J. Chen, Lin, \& Zheng, 2016).

Component . Andrographis paniculate is the dried above-ground part of Andrographis paniculata (Burm. 
f.) Nees. It is commonly used in the treatment of respiratory diseases such as colds, coughs, sore throat and other symptoms. It has antipyretic, anti-inflammatory, immune enhancement, cardiovascular protection, and anti-tumor effects. It is commonly used in respiratory disease treatment, and 3-Dehydroandrographolide (3-DA) is an important active ingredient of it. The study has revealed that 3-DA attenuated the release of proinflammatory cytokines IL-6 and TNF- $\alpha$ in LPS-stimulated RAW 264.7, inhibited the degradation and phosphorylation of $\mathrm{I} \varkappa \mathrm{B} \alpha$, and inhibited the nuclear translocation of NF- $\chi \mathrm{B}$ p65 and Akt Ser473 phosphorylation, increased $\alpha 7 \mathrm{nAChR}$ expression level and could bind to $\alpha 7 \mathrm{nAChR}$. MLA and $\alpha 7 \mathrm{nAChR}$ siRNA counteracted the anti-inflammatory effect of 3-DA. In LPS-induced ALI mice, 3-DA reduced inflammatory cytokines and lung water content, which were related to the inhibition of neutrophil and macrophage infiltration and activation of the NF- $x \mathrm{~B} /$ Akt pathway, which was weakened by MLA (Lu et al., 2018). Therefore, 3 -DA can exert anti-inflammatory effects on ALI through CAP, and $\alpha 7 \mathrm{nAChR}$ seems to be a potential target.

\section{2 | Sepsis}

Sepsis is an infection of the systemic inflammatory response syndrome. The serious mortality rate is as high as 30\%-50\%, which is related to the lack of hemodynamic stability, abnormal platelets, multiple organ dysfunction and disseminated intravascular coagulation (Angus \& Wax, 2001). In recent years, sepsis has been redefined as a life-threatening organ dysfunction caused by the dysregulation of the host's response to infection (Singer et al., 2016). It has been an important cause of the death of major diseases worldwide, and it is closely related to cytokines dysregulation. Bacteria or LPS activates TLR4 to induce macrophages to release pro-inflammatory factors (cytokines, chemokines) and participate in neutrophils recruitment, but excessive systemic inflammation is the reason for the migration of neutrophils into the infection focus, thereby infiltrating organs and causing failure. The efferent vagus nerve activates $\mathrm{ACh}$ and stimulates the splenic nerve to release NE, which in turn interacts with $\beta 2 \mathrm{AR}$ expressed in T lymphocytes. Furthermore, ACh activates $\alpha 7 \mathrm{nAChR}$ in macrophages, inhibits NF- $\chi \mathrm{B}$ nuclear translocation, and inhibits inflammatory mediators release (Kanashiro et al., 2017). Pavlov (Pavlov \& Tracey, 2006) found that the transmission of certain signals through vagus nerve in brain reduced the pro-inflammatory cytokines production and improved the survival rate of sepsis models. It is also an earlier report that the CAP may be involved in the improvement of sepsis. In the early stage of sepsis, CAP is stimulated mainly by stimulating the mAChR receptors of monocytes (stimulating peripheral $\alpha 7 \mathrm{nAChR}$ and central mAChR). Therefore, CAP plays an anti-inflammatory role in sepsis, and $\alpha 7 \mathrm{nAChR}$ mRNA level in peripheral blood monocytes can also be detected as clinically relevant markers in patients with sepsis. That is, the higher the $\alpha 7 \mathrm{nAChR}$ expression, the better the inflammation control and prognosis (Cedillo et al., 2015).

CHM prescriptions. Huang-Lian-Jie-Du-Decoction has anti-inflammatory, antibacterial, antihypertensive, and anti-cerebral ischemia effects. It is commonly used to treat sepsis, pneumonia, urinary system infection, dysentery, Japanese encephalitis, etc., which has been used more than 1700 years. It is commonly used to treat sepsis, its therapeutic effect on cecal ligation and puncture (CLP), and the efficacy of four variants of prescription (original prescription removes one herb respectively). The results showed that the original prescription had the best effect, mainly through enhancing CAP and inhibiting HMGB-1/TLR4/NF- $x \mathrm{~B}$ pathway (D. Xu, Lv, Wang, Yang, \& Kong, 2017). Shenfu injection is derived from the ancient prescription "Shenfu Decoction", which is commonly used in clinical emergency medicine. It is a traditional CHM preparation made from Ginseng Radix Et Rhizoma Rubra and Aconiti Lateralis Radix Praeparata. Ginsenosides and aconitum alkaloids are important active ingredients. The injection has pharmacological activities such as immune regulation, anti-heart failure, anti-shock, protection of ischemia-reperfusion injury, regulation of blood coagulation system, etc., and is mainly used for shock, sepsis, heart failure, and acute pancreatitis. Shenfu injection has effects on NF- $\chi \mathrm{B}$, MAPK and AKT pathways. Shenfu injection significantly reduced serum ALT and AST, liver TNF- $\alpha$ levels in LPS-induced sepsis rats, increased liver ACh level and ChAT activity, reduced pathological liver cell edema, inflammatory cell infiltration, necrosis, and so on. It indicates that it may be achieved by affecting CAP, that is, increasing the activity of ChAT to increase ACh content, inhibiting TNF- $\alpha$ expression and thus exerting a protective effect on sepsis (Hong, 2016). 
Rheum palmatum is the dried roots and rhizomes of Rheum palmatumL, Rheum tanguticum Maxim. Et Balf, and Rheum officinaleBaill., which contains active ingredients such as rhein, emodin, and aloe-emodin. It is effective against ALI, acute severe hepatitis and multiple organ dysfunction caused by endotoxin. The combination of Rheum palmatum and Scutellariae Radix is an important basis for many heat-clearing compounds and has a good therapeutic effect on sepsis. Li studied the impact of drug pair Rheum palmatumScutellariae Radix on CAP. Rheum palmatum and drug pair significantly inhibited the increase of body temperature and serum NO in endotoxemia model rats, and the effect of drug pair was stronger than that of Rheum palmatum, while the antipyretic effect of Scutellariae Radix and NO level reduction were not significant. They all significantly increased the vitality of lung ChAT and AChE in endotoxemia model rats. Rheum palmatum and Scutellariae Radix had similar strengths to improve lung ChAT activity and were stronger than drug pair; Scutellariae Radix had a higher effect on lung AChE than in Rheum palmatum and drug pair. The serum ACh level improvement of Rheum palmatum was stronger than Scutellariae Radix, and Scutellariae Radix was stronger than the drug pair. Therefore, after compatibility application of two herbs, it can increase the absorption of rhein and baicalin in endotoxin rats, but the effect on CAP is relatively weak (Fanfan Li, 2013). Due to the low dose of drugs used in this experiment, its specific mechanism of action does not exclude the relationship with CAP, its research still needed.

Extracts . Astragalus polysaccharide is an effective component of Astmgali Radix (the root of Astragalus propinquus Schischkin). Astmgali Radix has the functions of regulating immunity, anti-oxidation, anti-virus, enhancing myocardial function, protecting liver, anti-cancer, etc. It is often used clinically for pulmonary heart disease, coronary heart disease, tuberculosis, cerebral infarction, tumors, etc. Astragalus polysaccharide has antiviral, antibacterial and immune function enhancement effects. It combined with ibuprofen in the treatment of CLP septic rats, significantly reduced the production of TNF- $\alpha$ and IL-6, and increased $\alpha 7 \mathrm{nAChR}$ mRNA expression and the release of serum ACh. Which indicating that it is through $\alpha 7 \mathrm{nAChR}-$ mediated CAP to suppress sepsis (L. Liu, Chen, Xu, Hou, \& Mo, 2017).

Component . Sepsis can also cause brain damage during systemic infections (H. Xu, Turnquist, Hoffman, \& Billiar, 2017). Emodin is an important active ingredient of Polygonaceae plant Rheum palmatum, Polygoni cuspidati rhizome et radix, etc. It has anti-inflammatory, antibacterial, immune regulation, and vasodilator effects. And it is widely used in clinical applications, such as Japanese encephalitis, mumps, urinary tract infection, pneumonia, and otitis media. Emodin has obvious anti-inflammatory effects, reduce tissue and organ damage, and excessive inflammation caused by LPS (X. Dong et al., 2016). It is also revealed that have neuroprotective effects on acute brain injury caused by sepsis. That is, emodin significantly reduced the degree of brain damage, reduced the levels of S100 $\beta$, IL-6, TNF- $\alpha$, nerve-specific enolase in plasma, and reduced the levels of lactic acid and AChE in brain (Y. Dong, Liu, Zhang, \& Tang, 2019). The mechanism may be involved in CAP activation and inhibition of inflammation.

\section{3 | Inflammatory diseases of brain}

\subsection{1 | AD}

Among brain diseases, the incidence of dementia is getting higher and higher, and it is also related to CAP. The incidence of $\mathrm{AD}$ has increased in recent years. $\mathrm{AD}$ is a degenerative disease of the central nervous system. In addition to $\beta$-amyloid plaque deposition, cholinergic nervous system function damage, oxidative damage, and inflammation are also essential features of AD brain pathology. The study has found that the functions of ChAT and AChE in the cerebrospinal fluid and brain tissue of patients, as well as the synthesis, release, and uptake of ACh decreased (Tohgi, Abe, Hashiguchi, Saheki, \& Takahashi, 1994), and BChE activity increased (Perry, 1986). Decreased activity of the cholinergic system, especially projection abnormalities caused by progressive degeneration of cholinergic basal forebrain neurons, and decreased levels of ACh and ChAT in brain are important causes of $\mathrm{AD}$, the early stage of $\mathrm{AD}$ has been significantly reduced (Pappas, Bayley, Bui, Hansen, \& Thal, 2000). mAChR increases the $\alpha$-secretase pathway of amyloid precursor protein (APP) and exacerbates APP's non- $\beta$ amyloid peptide (A $\beta$ ) pathway metabolism (Nitsch, Slack, Wurtman, \& Growdon, 1992), while nAChR also increases APP expression and decreases A $\beta$ (Mousavi \& Hellström- 
Lindahl, 2009). In the early stage of $\mathrm{AD}$, a low concentration of $\mathrm{A} \beta$ activates hippocampal astrocytes to protect nerves. While in the middle and late stages, it accumulates too much to form a vicious circle, and a large amount of $A \beta$ is deposited in a feedback manner (Qi Wang \& Zhou, 2011). A $\beta$ and $\alpha 7 n A C h R$ have high affinity and combine to form a complex, thereby blocking neurotransmitter transmission and signal transmission, causing nerve cell death. $\alpha 7 \mathrm{nAChR}$ in astrocytes can regulate cell proliferation activation and inflammatory response, and its specific agonists and antagonists resist the combination of $\mathrm{A} \beta$ and $\alpha 7 n A C h R$, thereby alleviating AD-like lesions (H. Y. Wang et al., 2010). For example, PNU-282987 activates $\alpha 7 n A C h R$, attenuates $A \beta$-induced apoptosis and $A \beta$ deposition, increases the expression of synapse-related proteins and maintains the synapse morphology, which is related to the pathway that activates calmodulin (CaM)-calmodulin-dependent protein kinase II (CalMKI1)-cAMP response element binding protein (X. L. Wang et al., 2020). Therefore, the treatment of AD by activating CAP, on the one hand, it regulates the release of neurotransmitters by $\mathrm{nAChR}$ in presynaptic membrane to improve learning and memory, and nAChR excitatory neurons in the post-synaptic membrane maintain normal responses (Dajas-Bailador \& Wonnacott, 2004). Whereas, cholinergic receptors play an anti-inflammatory role through NF- $x \mathrm{~B}$, MAPK and JAK/STAT pathway to reduce the chronic inflammation of AD brain. Among the currently approved treatments for $\mathrm{AD}$, cholinesterase inhibitors (ChEI) are the most used, which is beneficial to restore the synaptic concentration of $\mathrm{ACh}$ and alleviate $\mathrm{AD}$ symptoms without causing too many side effects. The application and excavation of CHM in $\mathrm{AD}$ is also the direction of many scholars in recent years, and more drugs are showing potential therapeutic (Figure 3).

In addition, $\mathrm{mAChR}$ in central nervous system is also related to AD. The decreased coupling of M1 mAChR and $\mathrm{G}$ protein is the cause of a cognitive decline in $\mathrm{AD}$ patients. Activation of M1, M3 mAChR, or its downstream protein kinase $\mathrm{C}(\mathrm{PKC})$ molecules can significantly increase APP secretion and reduce A $\beta$ (Tsang et al., 2006). Both $\alpha 7 \mathrm{nAChR}$ activation and M1 mAChR activation down-regulate GSK3 $\beta$ and reduce the hyperphosphorylation of tau protein (Figure 4) (Bitner et al., 2009; Caccamo et al., 2006), thereby reducing neurofibrillary tangles. Among them, tau protein is a key driver of AD neurodegeneration and predict late brain atrophy (La Joie et al., 2020).

CHMprescriptions. Mailuoning injection is a preparation developed on the basis of "Simiao Yongan Decoction", which has the effects of anticoagulation, thrombolysis, spasmolysis, expansion of blood vessels, and improvement of microcirculation. It is used to treat thrombotic occlusive diseases. Mailuoning significantly increased the mRNA expressions of $\alpha 7 \mathrm{nAChR}, \mathrm{M} 3 \mathrm{mAChR}, \mathrm{ER} \alpha$, and NMDAR1 in the temporal cortex of early AD rats, which had no significant effect on M1mAChR mRNA expression, and protected nerves (Tian, 2009). Naoling Decoction could delay the disease development and improve life quality in AD treatment. It has a certain effect on memory ability and hemodynamic changes. Researchers have found that it inhibited the expression of TNF- $\alpha$, IL- $1 \beta$ and IL- 6 by inhibiting the NF- $\chi \mathrm{B}$ pathway and ASC-dependent inflammasome in hippocampus, normalized chromogranin A level in hippocampus and attenuated the activation of microglia and astrocytes induced by $\mathrm{A} \beta_{1-42}$ (Xia et al., 2017). Simultaneously, Naoling decoction dramatically up-regulated the expression of $\alpha 7 \mathrm{nAChR}$ and $\alpha 4 \mathrm{nAChR}$ on cell membrane of hippocampal CA3 area of $\mathrm{AD}$ model rats induced by $\mathrm{A} \beta_{1-42}$, inhibited $\mathrm{A} \beta$ deposition, improved learning memory and cognitive ability. In addition, CA3 area is the central area of learning and memory. Naoling decoction can reduce the pyknosis of pyramidal cells in CA3 area (W. Jin, 2010). Among them, $\alpha 4 \mathrm{nAChR}$ is the main subtype of $\alpha 42 \beta$. There is a loss of $\alpha 42 \beta$ neurons in hippocampus, frontal lobe, temporal cortex, and subcortex of AD patients. Stimulation of $\alpha 4 \mathrm{nAChR}$ can affect inducible nitric oxide synthase formation, reduce apoptosis and inflammation caused by NO synthesis, and thus protect nerve cells (Takada-Takatori et al., 2009). Tianshen Yizhi recipe is a preparation developed according to $\mathrm{AD}$ that has the functions of invigorating the spleen and "Qi", soothing the nerves, calming liver and eliminating wind, promoting blood circulation and removing blood stasis, and resuscitating. It against $\mathrm{A} \beta$-induced decrease in $\alpha 3 \mathrm{nAChR}$ and $\alpha 7 \mathrm{nAChR}$ protein levels and low expression of $\alpha 7 \mathrm{nAChR}$ mRNA, weakened cell damage and increased lipid peroxidation caused by $A \beta_{25-35}$ (Gu et al., 2007). Liuwei Dihuang Decoction regulates immune system, regulates hippocampus and ability of learning and memory, corticosteroid-like effects, and lower blood lipids. It is widely used in clinical practice. It is a decoction of Liuwei Dihuang Pills, which is often used for cardiovascular and cerebrovascular 
diseases, menopause, Lumbocrural pain. Liuwei Dihuang Decoction-containing cerebrospinal fluid improved $\mathrm{A} \beta_{1-40}$ induced PC12 cell growth and cell activity, increased $\alpha 7 \mathrm{nAChR}$ protein expression and inhibited the neurotoxic effect of $\mathrm{A} \beta_{1-40}$ (Ma, Ma, Miao, Ma, \& Tian, 2008). Daicong solution is a preparation from affiliated hospital of Weifang medical college for the clinical treatment of AD. It can improve APP gene expression, lymphocyte proliferation and brain tissue structure in AD. Further research found Daicong solution increased M1, M3mAChR mRNA levels in brain and improved the learning and memory functions in $\mathrm{AD}$ rats (H. Wang et al., 2007).

There are also some prescriptions through a similar mechanism to AChE inhibitors in AD treatment. For example, Naosuikang (H. Dong et al., 2019) and Nao Yikang (Geng et al., 2008) (all are hospital preparations) used clinically for cerebral arteriosclerosis, sequelae of stroke, cerebral infarction, cerebral atrophy, senile dementia, etc. They regulate the cholinergic system (promoting ChAT expression, reducing AChE activity, increasing Ach synthesis) and increase neurotrophic factors levels (NGF, BDNF) in the brain, thereby improving the spatial memory ability in rats with vascular cognitive impairment model. Dangshen Yuanzhi powder is a modified prescription of Yuanzhi powder (clinical treatment of dementia and amnesia). The main herbs in prescription, Polygalae Radix, Codonopsis Radix and Acori Tatarinowii Rhizome all could improve learning and memory. Dangshen Yuanzhi powder exerts an anti-AD effect by up-regulating ChAT expression and inhibiting AChE expression in the CA1 region and cortex of mouse hippocampus (L. Yang, Zhao, Wang, Wang, \& Wang, 2020). Rhizoma Polygonati and Earth Worm mixtures increased ACh level and ChAT, SOD, GSH-Px activity in brain, reduced MDA level and AChE activity, and exerted anti-inflammatory and antioxidant effects through CAP (Y. Xiao, Zeng, Ouyang, Cheng, \& Chen, 2013).

Extracts. Polygalae Radix is the dried root of Polygala tenuifolie willd. It is often used clinically for neurological disorders, senile dementia, and concussion syndrome. Polygalae Radix reduce AChE activity and improve the learning and memory function in $\mathrm{AD}$ rats $(\mathrm{Mu} \& \mathrm{Li}, 2007)$. Tenuigenin (active saponins of Polygalae Radix) increased $\alpha 7 n A C h R$ expression in hippocampal CA1 region of AD rats (D. Zhao et al., 2012), reduced AChE activity, increased ACh level of brain, thereby improving the learning, memory and cognitive ability in aging model mice (Q. Chen, Cao, \& Zhang, 2002; Zeng, Deng, Yan, Liu, \& Tang, 2009). Lycii Fructus is one of the most common traditional Chinese medicine health products in daily life. It has immune enhancement, anti-fatty liver, and cholinergic effects, and is clinically used for tumors, diabetes, hyperlipidemia, etc. Studies have found that it improved cognitive function in AD, up-regulated $\alpha 7 \mathrm{nAChR}$ expression in aging mice, increased serum SOD activity, reduced MDA level, and improved cognitive memory function (Sun, Miao, Wang, Qin, \& Chen, 2010). Its main component, lycium barbarum polysaccharides, reduced $A \beta_{1-40}$-induced astrocytes TNF- $\alpha$, IL-6 levels increase and $\alpha 7 n A C h R$ high expression. While its effect is similar to nicotine, and astrocytes proliferation activity is still significantly increased (Ren et al., 2016).

Component . Tripterygium wilfordii (the root of Tripterygium wilfordii Hook. f.) has anti-inflammatory, immune-regulating, anti-tumor, and neuroprotective effects. It is clinically used for nephropathy, autoimmune diseases, rheumatoid arthritis, $\mathrm{AD}$, etc. Triptolide is the epoxyditerpene lactone with the highest activity of Tripterygium wilfordii. It is also one of the most important anti-inflammatory and immunosuppressive components. It can regulate the expression of cytokines and $\mathrm{NF}-x \mathrm{~B}$, and inhibit the proliferation reaction of $\mathrm{T}$ and $\mathrm{B}$ lymphocytes. Triptolide inhibited A $\beta$-induced activation of astrocytes, reduced inflammatory mediators release, reduced cholinergic fibers damage, and improved neurodegenerative diseases such as $\mathrm{AD}$ (Huang, 2010). Bilobalide is an important component of Ginkgo biloba, a sesquiterpene lactone and a drug for nervous system and psychosis. It has a curious effect on stupidness caused by old age. Bilobalide is also commonly used for neuropathy, encephalopathy, and myelopathy. It has a protective effect on the cognitive impairment of $\mathrm{AD}$ rats induced by $\mathrm{A} \beta_{1-40}$, which regulated the expression of cholinergic neurotransmitters, reduced the level of oxidative stress and anti-inflammatory (X. Jin, Wang, Xie, Zhang, \& Liu, 2019).

AChEI . According to cholinergic deficiency theory of AD, neural ACh is responsible for learning and cognition. AChE is a key enzyme that affects ACh and has become a significant target in AD drug development. 
There are four AChEI drugs in five AD drugs approved by the FDA, namely Tacrine, Donepezil, Rivastigmine and Galantamine. CHM prescriptions, single herb and components are critical sources of AChEI, and many active ingredients are considered as potential therapeutic drugs for AD because of their inhibitory effect on AChE. This review sorts out CHM and its ingredients with IC50 less than $0.05 \mu \mathrm{mol} / \mathrm{mL}$ (Table 2, Chinese medicines that only detect the inhibition rate are not included). Galantamine and Huperzine A (H. Y. Zhang, Liang, Tang, He, \& Bai, 2002) (already listed in China) are important AChEI extracted and developed from CHM. Galantamine is a phenanthridine alkaloid extracted from Amaryllidaceae plants. In addition to interfering with APP metabolic process, it reduces the production of A $\beta$. It is also the reversibility of the second-generation AChEI, as allosteric enhancement ligands, can activate nAChR, promote the release of ACh from cholinergic terminals, and protect the survival and function of neurons (Anand \& Singh, 2013; Samochocki et al., 2003). Catechins in green tea have been revealed to exert anti-AD effects through antioxidant, anti-inflammatory, affecting PKC and neurotransmission-related properties (Ide, Matsuoka, Yamada, Furushima, \& Kawakami, 2018). Meanwhile, Epigallocatechin Gallate and Epigallocatechin in green tea inhibit $\mathrm{AChE}$ and $\mathrm{BuChE}$, and different catechins synergistically inhibit AChE. These two enzymes regulate cholinergic neurotransmission. BuChE is responsible for most of ACh metabolism in late stage of AD. Although their inhibition rate is not as high as that of galantamine, they have relatively fewer side effects (Okello \& Mather, 2020). In addition, through experiments on AChE inhibition and molecular docking studies, it was revealed that the following components have a certain inhibitory effect on AChE: Huanglianjiedu decoction (J. Song, Wang, Si, \& Bian, 2010), aqueous extract of Cortex Phellodendri, aqueous extract of Magnoliae Officmalis Cortex (Shi, Wang, \& Liu, 2011), volatile oil of Radix Peucedani (Yamin Liu, Song, Li, Jiang, \& Pan, 2012), polycyclic-meroterpenoid of Ganoderma (Peng et al., 2014), lanostane-type triterpene of Ganoderma (Lee et al., 2011), berberine (Xiang, Yu, Yang, Yang, \& Ding, 2009), columbamine, dauricine, jatrorrhizine (P. Li et al., 2019), palmatine (H. Zhao et al., 2016), carinatumin A and B (Choo et al., 2007), geissoschizine methyl ether (Z. D. Yang et al., 2012), stenine A and B (Lai et al., 2013), volvalerenal acid K (H. W. Chen et al., 2016), leoheteronin A, leopersin G (Hung, Luan, Vinh, Cuong, \& Min, 2011), icariin (Xin, Euikyung, Tian, Lin, \& Guo, 2001), tOMe-byakangelicin, byakangelicol (Seo et al., 2013), demethoxycurcumin, bisdemethoxycurcumin (Ahmed \& Gilani, 2009), ginsenoside (Choi et al., 2016). These active ingredients are mainly flavonoids, alkaloids, phenols, terpenes, saponins, etc., which has the potential to treat AD. Since the screening of various ingredients is limited to in vitro experiments and molecular docking, complex conditions in vivo may have low bioavailability, difficulty in penetrating the blood-brain barrier, and poor drug-forming properties. These ingredients need to be further screened. In addition, many drug researches have limited the mechanism of AChEI treatment of AD to the role of ACh in learning and cognition, and there are relatively little research and discussion on the anti-inflammatory effects of cholinergic.

\subsection{2 | Vascular dementia}

Vascular dementia (VD) is different from AD. It is a severe cognitive dysfunction syndrome caused by ischemic stroke, hemorrhagic stroke, and cerebrovascular diseases that cause hypoperfusion of brain regions, such as memory, cognition, and behavior. Immunity and inflammation are also involved in the pathogenesis of $\mathrm{VD}$, and the inflammatory response induced by cerebral ischemia is an important factor leading to cerebral ischemic injury. The relationship between VD and CAP is mainly related to the role of $\mathrm{ACh}, \mathrm{AChE}$ activity, synaptic changes in the central cholinergic system, and inflammation regulation.

The clinical application of Bushen Xingnao decoction has proved to be effective in VD treatment. It is the clinical experience formula of Professor Feng Yinman, a national outstanding contribution expert. It works by improving free radical metabolism, amino acid neurotransmitter content, and inhibiting cell apoptosis. Animal experiments have shown that it significantly reduced the level of VEGF, TNF- $\alpha$ and IL-1 $\beta$ in VD rat brain, and the level of anti-inflammatory cytokines IL-10 and TGF- $\beta$, down-regulated NF- $\chi \mathrm{B}$ expression, increased ChAT activity, and reduced AChE activity (J. Hu, He, Zhang, \& Zhao, 2011). It may alleviate vagal nerve suppression, promote increased ACh synthesis, reduce inflammation and reduce brain damage. Besides, the drug reduced brain adhesion factors ICAM-1, VCAM-1, E-selectin, P-selectin 
to reduce ischemia-reperfusion injury. Therefore, Bushen Xingnao decoction activates CAP, blocks NF- $\chi \mathrm{B}$ pathway, and regulates the expression of inflammatory cytokines and adhesion factors (J. Hu, 2011). Bushen Jiannao Recipe is an improved recipe of Dihuangyinzi. It can improve learning and memory ability, change the content of amino acid neurotransmitters, and inhibit cell apoptosis in VD treatment. It increased ACh level in the cortex and hippocampus, and promoted the expression of ERK1 and ERK2 in hippocampal CA1 area, regulate CAP to reduce inflammation (Yonghui Liu, Li, \& Zheng, 2012). Dihuangyinzi is often used for chronic diseases such as AD, VD, advanced hypertension, cerebral arteriosclerosis, stroke sequelae, and myelitis. Dihuangyinzi could treat VD and AD caused by chronic cerebral hypoperfusion, increase the activity of total antioxidant capacity in hippocampus, reduce the apoptosis rate, and significantly reduce hippocampal AChE activity and increase ChAT activity (L. Bai, Zhang, Wu, \& Yang, 2011). Modified Yiqi Congming decoction (X. Bai, Peng, Tang, Yang, \& Zhang, 2016) and total flavone of Hawthorn leaf (Mao, Miao, $\mathrm{Wu}, \&$ Chen, 2014) increased ACh level in rats hippocampus, reduced AChE level, and improved learning and memory function of VD rats. Pueraria is an isoflavones derivative in Puerariae Lobatae Racix (Pueraria lobata (Willd) Ohwi). It has the effects of reducing fever, calming, increasing coronary blood flow, and improving immunity. It is clinically used for hypertension, coronary heart disease, angina, etc. Puerarin relieved neurological damage in rats with cerebral ischemia-reperfusion injury, improved the infiltration of inflammatory cells in brain hippocampus, reduced the level of IL-1 $\beta$, IL-6, and TNF- $\alpha$ in brain, and increased the level of IL-10. $\alpha$-bungarotoxin can block its anti-inflammatory effects, indicating that it may activate CAP (M. Wang, Mei, Zeng, \& Liu, 2012).

\subsection{3 | Traumatic brain injury}

Inflammation and apoptosis are pathological features of secondary brain mechanical injury (TBI), overexpression of inflammatory cytokines such as IL-6 and TNF- $\alpha$ can induce apoptosis and death. The focus of modern therapy is to control and reduce secondary injury (Zhai et al., 2015).Arctium lappa L. is a diuretic, antiinflammatory and detoxifying CHM. Its active ingredient arctiin has anti-inflammatory and anti-apoptotic effects. Its effect on neuroprotection is mainly related to microgliosis and pro-inflammatory cytokine production, active apoptotic cytokine production, caspase-3 activity and neuronal cell death significantly reduced. Arctiin reduced levels of TNF- $\alpha$, IL- 6 and the number of TUNEL+ apoptotic cells surrounding scratches, increased IL-10 levels, up-regulated the levels of miRNA-16 and miRNA-199a. Thereby it reducing the upstream IKK $\alpha$ and IKK $\beta$ protein expression and inhibiting the activity of NF- $\chi \mathrm{B}$ pathway. In addition, it caused increased miRNA-199a to inhibit AChE and enhanced cholinergic signal (Swarup, Ghosh, Mishra, \& Basu, 2008).

\section{4 | Cardiovascular diseases}

\subsection{1 | Atrial fibrillation}

Atrial fibrillation (AF) is also associated with inflammation, and inflammatory cytokines may be related to fibrosis and the expression of current channel subunits that promote AF-related electrical remodeling (Guo, Lip, \& Apostolakis, 2012; Y. F. Hu, Chen, Lin, \& Chen, 2015; Shang et al., 2008). Sensong Yangxin capsule is clinically used for arrhythmia, coronary heart disease, ventricular premature beats, paroxysmal atrial fibrillation, and the effect on action potential duration and atrial conduction capacity is related to the effect on autonomic nerve (Feng et al., 2009). The study revealed that it inhibited the effective atrial refractory period of dogs with long-term intermittent atrial pacing-induced by implantation of a cardiac pacemaker, and inhibited the increase of sympathetic nerves and the up-regulation of TNF- $\alpha$ and IL- 6 expression. In addition, it inhibited the long-term intermittent atrial pacing-induced reduction of ACh and $\alpha 7 n A C h R$ proteins, indicating that it may be related to the imbalance of autonomic nerve activity and CAP (H. Y. Zhao et al., 2017). 


\subsection{2 | Myocardial ischemia reperfusion injury}

CAP inhibits NF- $x \mathrm{~B}$ pathway and $\mathrm{NF}-\varkappa \mathrm{B}$ is a regulatory protein that is involved in the earlier process of myocardial ischemia reperfusion injury (MIRI). It regulates the gene transcription process of various cytokines, inflammatory mediators, and adhesion molecules to control its biosynthesis. Breviscapine is a flavonoid component in Erigeron breviscapus, which is commonly used in coronary heart disease, angina pectoris, and acute myocardial infarction. Its intervention substantially increased the expression of NF- $\chi \mathrm{B}$ p65 and $\alpha 7 n A C h R$ protein in MIRI rats and reduced $\mathrm{x} \varkappa \mathrm{B}-\alpha$ expression (Ding et al., 2018). NF- $\chi \mathrm{B}$ resists apoptosis by regulating a series of gene transcription and expression, so breviscapine effectively inhibits cardiomyocyte apoptosis through CAP-mediated NF- $x$ B pathway.

\subsection{3 | Obesity-related hypertension}

The expression of SOCS3 and protein tyrosine phosphatase 1B (PTP1B) inhibitors was upregulated by active IKK $\beta / N F-x \mathrm{~B}$ signaling in hypothalamus and increased proinflammatory cytokines. As negative regulators of leptin signaling, both SOCS3 and PTP1B induce central leptin resistance by disrupting JAK2/STAT3 phosphorylation. Leptin cannot effectively regulate energy homeostasis while maintaining its ability to stimulate the cardiovascular/renal sympathetic nervous system, leading to sympathetic nerve-mediated hypertension (de Git \& Adan, 2015; Mark, 2013; X. Wang et al., 2012). Therefore, low levels of pro-inflammatory state and leptin resistance are potential mechanisms resulting in obesity-induced hypertension. Astragaloside IV is one of the main active ingredients in Astragalus mongholicus, it has the effects of enhancing immunity, anti-virus, anti-stress, and improving heart and lung function. Which inhibited the production of pro-inflammatory cytokines in the central nervous system and the activation of the IKK $\beta / \mathrm{NF}-\mathrm{KB}$ pathway, enhanced leptin sensitivity, and improved metabolic disorders. It alleviated leptin resistance by increasing p-STAT3, LepRb mRNA and POMC mRNA and decreasing p-PI3K, SOCS3 mRNA, and PTP1B mRNA, up-regulating $\alpha 7 n A c h R$ in hypothalamus and adipose, inhibiting IKK $\beta / N F-K B$ signaling and proinflammatory cytokines. So that Astragaloside IV prevents obesity-induced hypertension is associated with increased $\alpha 7 n A C h R$ expression (P. Jiang et al., 2018).

\subsection{4 | Shock}

The body's response to the decrease in effective circulating blood volume is a pathological process of metabolism and cell damage caused by insufficient tissue perfusion and various neuro-humoral factors are involved in the occurrence and development of shock. Whether it is septic shock or hemorrhagic shock, the body will be damaged by pathogens or ischemia and cause organ damage, resulting in an inflammatory response, so the treatment of shock by CAP is also possible. Anisodamine is a belladonna alkaloid extracted from Scopolia tangutica Maxim. It is a $\mathrm{mAChR}$ antagonist and is usually improve circulatory diseases such as shock, hypertensive encephalopathy, lung disease, acute nephritis and heart failure, etc., and its strength is similar to that of atropine. It blocks mAChR, causing ACh to return to $\alpha 7 \mathrm{nAChR}$, resulting in ACh-mediated $\alpha 7 n A C h R$ activation and an increase in CAP activity (T. Zhao, Li, Liu, Su, \& Shen, 2011).

\section{5 | Arthritis}

Rheumatoid arthritis (RA) is a common autoimmune disease. Existing research indicates that CAP may be an important treatment for RA. The patient's joint synovium expresses various inflammatory mediators such as TNF- $\alpha$, IL-1 $\beta$. After NF- $\chi \mathrm{B}$ activation, it enhances the gene transcription level of the inflammatory mediators, so that the inflammatory response continues (Makarov, 2001). And initiate the transcription of genes such as Bcl-2, NOS, and apoptosis inhibitory protein, causing abnormal apoptosis of fibroblast-like synoviocytes (FLS). FLS accumulates in cartilage and bone adhesion to secrete MMP and pro-inflammatory

factors, which promote immune inflammation and lead to bone destruction (S. Bai et al., 2004; Feldmann et al., 2002). Therefore, FLS is the pathological center of RA, which respond to inflammation and stimulate inflammation to destroy articular cartilage and bone. In the collagen-induced arthritis rat model, $\alpha 7 n A C h R$ expression level in joints and spleen was the highest, which proved that CAP is involved in the occurrence and 
development of RA inflammation (Z. Li et al., 2019). JAK/STAT pathway is also an important mechanism of an inflammatory response and immune response in the pathogenesis of RA. In RA inflammatory response, a large amount of $\mathrm{ACh}$ is released after vagus nerve excites, the catalytic activity of the intracellular domain is activated, a large amount of JAK2 is accumulated around $\alpha 7 \mathrm{nAChR}$. Maanen (van Maanen et al., 2009) found that cutting off vagus nerve worsen RA condition. However, after intraperitoneal injection of the $\alpha 7 \mathrm{nAChR}$ selective agonist AR-R17779 or nicotine, the release of TNF- $\alpha$ in mice synovial was significantly reduced, which delay progression and reduce joint bone destruction. Activating $\alpha 7 \mathrm{nAChR}$ with nicotine reduces joint degradation caused by monosodium iodoacetate. By inhibiting p38, extracellular regulation of MIA or IL$1 \beta$-induced p65-activated Erk1/2 and JNK-activated MAPK phosphorylation and NF- $\varkappa$ B Phosphorylation, and these effects are also reversed by selective antagonist MLA, suggesting that activation of $\alpha 7 \mathrm{nAChR}$ may treat arthritis (Y. Liu et al., 2015).

CHM prescriptions. Hebi Recipe is a clinical prescription for early RA, which improves patients' joint swelling, pain, rheumatoid, etc., and reduces synovial membrane thickening and improves the symptoms of malaise related to the autonomic nervous system. It up-regulated $\alpha 7 \mathrm{nACh}$ expression to activate CAP, activated JAK2/STAT3 signaling pathway, reduced TNF- $\alpha$, IL-6, IL-17 levels, and reduced joint swelling (Xing et al., 2018).

Extracts. Tripterygium wilfordii is widely used in the treatment of RA. Wilforlide A, triptolide and celastrol are active ingredients for anti-inflammatory and immunomodulation. Tripterygium wilfordii polyglucoside is a compound preparation of multiple components. It reduced the expression of IL-17 and HMGB1, participated in regulating CAP activation, and inhibited the activation of downstream NF- $\chi \mathrm{B}$ and JAK2/STAT3 pathway, reduced NF- $\varkappa$ B p65 expression (W. Liu \& Zhang, 2019).

Components. Sinomenine is the principal active ingredient of Caulis Sinomenii in anti-rheumatical CHM, has anti-inflammatory and immunomodulatory effects, and is commonly used in RA treatment (Q. Wang \& Li, 2011). It inhibited pro-inflammatory cytokines production and TLR4/MyD88/NF- $x \mathrm{~B}$ pathway, and prevented IL-1 $\beta$-induced inflammation of human fibroblast-like synoviocytes (Yao, Zhao, Zhao, \& Cai, 2017). The knockout of $\alpha 7 \mathrm{nAChR}$ and $\alpha 7 \mathrm{nAChR}$ antagonist eliminated the effect of sinomenine on TNF- $\alpha$ and IL-6 production and NF- $x \mathrm{~B}$ activation stimulated by LPS in macrophages (Yi et al., 2015). It mainly inhibited macrophage CD14/TLR4 expression and intracellular free calcium levels through $\alpha 7 n A C h R$, activated JAK2/STAT3 pathway to suppress inflammation (Zhu et al., 2019). It was further revealed that sinomenine has improved the systemic inflammation of collagen-induced arthritis (CIA) rats, which significantly reduced the effects of vagotomy or $\mathrm{nAChR}$ antagonists, and may bind to $\alpha 7 \mathrm{nAChR}$ through the interaction of residues Tyr184 and Tyr191, while mAChR antagonist had no effect. It showed that it mainly enhanced vasoactive intestinal polypeptide (VIP) production in the intestine and neuron-like cells in CIA rats by activating the $\alpha 7 n A C h R-P I 3 K / A K T / m T O R$ pathway. VIP also plays a key role in the anti-arthritis effect of sinomenine (Yue et al., 2018). Moreover, its mechanism was also related to the inhibition of FLS proliferation by regulating $\alpha 7 n A C h R$ expression through ERK/Egr-1 pathway (Yi et al., 2018). Therefore, sinomenine plays an

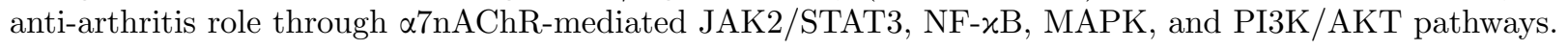

\subsection{Diabetes}

Diabetes is called "Xiao Ke" in traditional Chinese medicine, type 2 diabetes mellitus (T2DM) is a chronic metabolic disease. Insulin resistance decreases in the efficiency of insulin in promoting glucose uptake and utilization and often causes T2DM. Insulin resistance is related to oxidative stress, mitochondrial disorders, endoplasmic reticulum stress, etc (Hafizi Abu Bakar et al., 2015; Y. X. Li et al., 2015). The inflammatory response also plays a significant role. Before T2DM occurs, IL- $1 \beta$ and IL- 6 in blood circulation increase, and people with high inflammatory cytokines levels are more susceptible to T2DM (Spranger et al., 2003). The relationship between insulin resistance and inflammation may be attributed to the activation of JNK or IKK $\beta$ by inflammatory cytokines and NF- $x \mathrm{~B}$ activation. The phosphorylation of insulin receptor substrate 1 serine 307 inhibits PI3K-Akt, leading to the inhibition of glucose transporter synthesis, glycogen synthesis and degradation (de Luca \& Olefsky, 2008). Furthermore, CAP activation has an effect on insulin resistance 
caused by obesity and diabetes, and will be worsened after $\alpha 7 n A C h R$ knockout (Marrero et al., 2010). It is even more conjecture that $\mathrm{CAP}$ activated by $\alpha 7 \mathrm{nAChR}$ may influence insulin resistance. In addition, type 1 diabetes mellitus (T1DM) is an autoimmune disease driven by $\mathrm{T}$ cells, which leads to pancreatic $\beta$-cells death and insulin production loss. Specific AChEI prevents the development of hyperglycemia in C57BL/6 mice caused by MLD-STZ, which is associated with inhibition of Th17 cell infiltration into islets and reduction of IL-1 $\beta$, IL-6, IL-17 (George et al., 2016). It was further found that mAChRs are necessary for the protective effect of cholinergic stimulation in autoimmune diabetes (Fernández-Cabezudo et al., 2019).

Berberine is mainly present in Coptis chinensis, Phellodendron chinense, etc. It is an effective component of Coptis chinensis to lower blood sugar. Previous studies have concluded that it inhibits inflammation and improves insulin resistance(Lou et al., 2011). In addition, studies on AChE inhibiting the activity of benzylisoquinoline alkaloids indicate that berberine may be an inhibitor of AChE (D. K. Kim et al., 2004). Berberine up-regulated the expression of $\alpha 7 \mathrm{nAChR}$ mRNA and protein in 3T3-L1 cells, significantly inhibited the secretion of inflammatory cytokines TNF- $\alpha$, IL-1 $\beta$, IL-6, increased glucose uptake, inhibited AChE activity, and reduced pIKK $\beta$ Ser181/IKK $\beta$, NF- $x$ B p65 expression and IL-6 levels. It indicates that it may enhance glucose uptake in HepG2 cells and reduce inflammation and insulin resistance by inhibiting CAP and AChE, (F. Li et al., 2016; X. Zhou et al., 2015).

\section{7 | Gastrointestinal disease}

\subsection{1 | Postoperative ileus}

Postoperative ileus (POI) is a temporary intestinal coordinating movement disorder resulting from intestinal contents that cannot be effectively emptied and/or cannot tolerate oral feeding after surgery (Artinyan et al., 2008). Fuan granule is a compound of Yinchenhao Decoction and Dachengqi Decoction. It can effectively inhibit the occurrence of POI and reduce the length of hospital stay. In POI model rat, Fuan (3mL, enema) significantly inhibited the release of TNF- $\alpha$ and MCP-1 after surgery, and significantly improved small intestine propulsion rate and reduced gastric residual rate, showed a significant improvement effect on POI. The effect of applying Fuan granules after vagotomy is better than that when used alone, indicating that it may compete with ACh for receptors on CAP, which needs to be further verified (W. Chen, 2013). Dajianzhong Decoction comes from "Synopsis of the Golden Chamber", which is often used for digestive system diseases such as abdominal pain, bloating, and gastric motility disorders. The mechanism of Dajianzhong decoction, Ginseng radix, Zingiberis rhizome and Zanthoxylum fructus on POI is studied. The experiment revealed that they all significantly inhibited neutrophil infiltration, and Zingiberis rhizome significantly reduced neutrophil infiltration in 5-HT4R knockout mice, but not in $\alpha 7 \mathrm{nAChR}$ knockout mice. In addition, Zingiberis rhizome improved the effect of transient receptor potential anchor protein 1 (TRPA1) and mAChR antagonists on neutrophils inhibition. Therefore, the inhibitory effect of Dajianzhong Decoction on inflammation depends partly on the function of Zingiberis rhizome, which mainly released 5-HT by activating the TRPA1 channel of intestinal collateral cells, and released ACh by 5-HT4R acting on intermuscular plexus neurons (Endo et al., 2017; Endo et al., 2018). Meanwhile, $\alpha 7 \mathrm{nAChR}$ was activated to inhibit macrophage infiltration, and activate $\mathrm{mAChR}$ to inhibit neutrophil infiltration.

\subsection{2 | Acute pancreatitis}

Uncontrolled synthesis and release of cytokines is an important cause of tissue damage. CAP antiinflammatory signals can regulate the inflammation of acute pancreatitis. Chaiqin Chengqi Decoction (CQCQD) has a definite effect on the treatment of acute pancreatitis and POI in West China Hospital of Sichuan University, the mechanisms are related to remove gastrointestinal stagnation, bacteria and endotoxins, and protect the mechanical and immune barriers. In severe acute pancreatitis model rats, vagus nerve was suppressed, ACh synthesis was reduced, and the inflammatory response was severe. CQCQD treatment reduced serum IL-6, TNF- $\alpha$ and other inflammatory cytokines, reduced AChE, and increased serum ChAT, suggesting that it may be activated by CAP (Xue et al., 2006). At the same time, CQCQD was also found 
to activate CAP in patients with acute pancreatitis, reduced inflammatory mediators level, and reduced inflammatory response (You, 2007).

\subsection{3 | Stress gastric ulcer}

Pathogenic factors are multi-sourced, and autonomic dysfunction plays an important role in stress gastric ulcer. ChAT is a marker enzyme of the cholinergic nerve. Ulcer formation is one of the outcomes of acute inflammation, so inflammation is also importantly associated with gastric ulcers. Banxiaxiexin Decoction is derived from the clinical experience of treating spleen and stomach diseases in "Treatise on Febrile Diseases". It is often used for acute gastroenteritis, chronic gastritis, dyspepsia, and incomplete gastric pyloric obstruction. Banxiaxiexin Decoction and its decomposed formulas treated stress gastric ulcer in rats, reduced gastric mucosal bleeding, and the expression of ChAT on rat brain and gastric mucosa, indicating that Banxiaxiexin decoction may be improved by the anti-inflammatory effect of CAP (Z. Zhang, Si, Wu, $\mathrm{Xu}, \&$ Bai, 2005).

\section{5 | CONCLUSION AND PERSPECTIVES}

The interaction of nervous system and immune system is essential for regulating innate immune response and controlling inflammation. CAP has broad development prospects in the treatment of inflammatory diseases. With the in-depth study of CAP pathway, its relationship with various inflammatory diseases has not been fully elucidated, so the pharmacological effect of drugs through CAP has accounted for a large share of disease treatment, which is still unknown. Inflammatory diseases also include depression, shock, allergic asthma, colitis, cancer, and other diseases with high incidence rates. Many CHM that treats inflammatory diseases has not yet been studied whether they are related to CAP. It may become a potential treatment for such diseases. Therefore, it is necessary to thoroughly study the relationship among CAP, pathways, and diseases. Studying the mechanism of CHM in CAP is also more conducive to understanding its mechanism from a new entry point and promoting the clinical application of CHM. In the drug studies compiled in this review, most of them focused on the activation of $\alpha 7 \mathrm{nAChR}$ and the regulation of ACh level in CAP. The mechanism researches of most drugs are still needing to be explored for further applications. Characteristics of the multicomponent-multitarget-multipathway of CHM, more therapeutic drugs can be developed from CHM prescriptions or active ingredients. It has better clinical application value as an alternative therapy for CAP activation through secondary advance research.

Some researchers have suggested that COVID-19 may be a cholinergic system disease in the late stage of development. It has clinical manifestations of cytokine storm, insomnia, and thromboembolic complications, indicating that it is related to cholinergic dysfunction (Farsalinos et al., 2020). ACE-2 is the main receptor used by SARS-CoV-2 to enter the host cell and nicotine upregulates ACE-2 through $\alpha 7 n A C h R$ (Leung, Yang, \& Sin, 2020; Russo et al., 2020). So that it has become a possible treatment that changes the expression of ACE-2 through $\alpha 7 n A C h R$ antagonist to prevent SARS-CoV-2 from entering the cells. The present review found that Chinese medicines such as Liang-Ge-San, Huanglian Jiedu Decoction, Shenfu Injection, Scutellariae Radix, Coptidis Rhizoma, and total flavonoids of litchi have the effect of treating ALI and sepsis. In the COVID-19 epidemic, Huanglian Jiedu Decoction, Shenfu Injection, and other drugs have also been recommended for clinical using, which have achieved remarkable results. In the SARS epidemic, it has also been revealed that in the treatment of such major coronavirus infections, glucocorticoid drugs, ribavirin, alpha-interferon, lopinavir/ritonavir after long-term application, it will produce a certain degree of sequelae such as liver damage, pulmonary fibrosis, and femoral head necrosis. In the treatment of CHM, more emphasis is placed on increasing efficacy and reducing toxicity, improving the security of medication, enhancing self-immunity, and improving the ability to clear viruses. Therefore, CHM based on CAP exerting anti-inflammatory effect is also one of the treatment methods in COVID-19, which can reduce dosage or use of hormone drugs to a greater extent, reduce liver damage and sequelae, and the combination of Chinese and Western medicine is more conducive to overcoming such problems at an early date. The mechanism and 
clinical application need to be further explored.

Although there are no clinical drugs that have clinical side effects with $\alpha 7 \mathrm{nAChR}$ as the target, due to the limitations of cholinergic drugs, they have side effects on the organs under the parasympathetic nervous system. For instance, when acting on M2 mAChR may cause bradycardia, when acting on M3 mAChR may cause blood pressure drop, abdominal cramps caused by smooth muscle contraction and bronchial asthma, etc., and cholinergic drugs entering the brain may also affect nerves. Consequently, purely safe drugs do not exist, the usage and dosage of drug are crucial. In clinical applications, CHM emphasizes dialectical medicine to avoid contraindications (such as bronchial asthma, arrhythmia, intestinal resection, urinary tract obstruction, etc.). It is reasonably matched with medicines to enhance the therapeutic effect and reduce toxicity, and exert the advantage of the anti-inflammatory effect of CHM with accurate curative effect and small side effects. In summary, CAP is an important mechanism for inflammatory disease treatment with CHM. There are still a lot of research that needs to be explored in-depth, which can be utilized as a new perspective for clinical application.

\section{ACKNOWLEDGEMENTS}

This work was supported by the National Natural Science Foundation of China (82074094, 81473399, J1310034-09); Department Pharmacology, Sichuan Provincial Science and Technology, Sichuan Province Youth Science and Technology Innovation Team (2014TD0007); Xinglin Scholar Research Promotion Project of Chengdu University of TCM (CXTD2018014); the Open Research Fund of Chengdu University of Traditional Chinese Medicine Key Laboratory of Systematic Research of Distinctive Chinese Medicine Resources in Southwest China.

\section{CONFLICT OF INTEREST}

The authors declare no conflicts of interest.

\section{REFERENCES}

Agostoni, E., Chinnock, J. E., De Daly, M. B., \& Murray, J. G. (1957). Functional and histological studies of the vagus nerve and its branches to the heart, lungs and abdominal viscera in the cat. J Physiol, 135 (1), 182-205.https://doi.org/10.1113/jphysiol.1957.sp005703

Ahmed, T., \& Gilani, A. H. (2009). Inhibitory effect of curcuminoids on acetylcholinesterase activity and attenuation of scopolamine-induced amnesia may explain medicinal use of turmeric in Alzheimer's disease.Pharmacol Biochem Behav, 91 (4), 554-559.https://doi.org/10.1016/j.pbb.2008.09.010

Anand, P., \& Singh, B. (2013). A review on cholinesterase inhibitors for Alzheimer's disease. Arch Pharm Res, 36 (4), 375-399.https://doi.org/10.1007/s12272-013-0036-3

Angus, D. C., \& Wax, R. S. (2001). Epidemiology of sepsis: an update.Crit Care Med, 29 (7 Suppl), S109-116.https://doi.org/10.1097/00003246-200107001-00035

Artinyan, A., Nunoo-Mensah, J. W., Balasubramaniam, S., Gauderman, J., Essani, R., Gonzalez-Ruiz, C., . . . Beart, R. W., Jr. (2008). Prolonged postoperative ileus-definition, risk factors, and predictors after surgery. World J Surg, 32 (7), 1495-1500.https://doi.org/10.1007/s00268-008-9491-2

Bai, L., Zhang, X., Wu, M., \& Yang, R. (2011). Influence of Dihuangyinzi on learning and memory and AChE,ChAT of hippocampal in chronic cerebral hypoperfusion rats. Chin J Exp Trad Med Form, 17 (7), 207-209.https://doi.org/10.3969/j.issn.1005-9903.2011.07.063 
Bai, S., Liu, H., Chen, K.-H., Eksarko, P., Perlman, H., Moore, T. L., \& Pope, R. M. (2004). NF-xBregulated expression of cellular FLIP protects rheumatoid arthritis synovial fibroblasts from tumor necrosis factor $\alpha$-mediated apoptosis. Arthritis Rheum, 50 (12), 3844-3855.https://doi.org/10.1002/art.20680

Bai, X., Peng, Y., Tang, H., Yang, Y., \& Zhang, D. (2016). Effect of modified Yiqi Congming Decoction on praxiology and the content of Ach and AchE of hippocampal neurons in rats with vascular dementia $J$ Sichuan Trad Chin Med, 34 (5), 59-62.https://doi.org/CNKI:SUN:SCZY.0.2016-05-027

Bencherif, M., Lippiello, P. M., Lucas, R., \& Marrero, M. B. (2011). Alpha7 nicotinic receptors as novel therapeutic targets for inflammation-based diseases. Cell Mol Life Sci, 68 (6), 931949.https://doi.org/10.1007/s00018-010-0525-1

Bitner, R. S., Nikkel, A. L., Markosyan, S., Otte, S., Puttfarcken, P., \& Gopalakrishnan, M. (2009). Selective alpha7 nicotinic acetylcholine receptor activation regulates glycogen synthase kinase3beta and decreases tau phosphorylation in vivo. Brain Res, 1265, 65-74.https://doi.org/10.1016/j.brainres.2009.01.069

Borovikova, L. V., Ivanova, S., Zhang, M., Yang, H., Botchkina, G. I., Watkins, L. R., . . . Tracey, K. J. (2000). Vagus nerve stimulation attenuates the systemic inflammatory response to endotoxin. Nature, 405 (6785), 458-462.https://doi.org/10.1038/35013070

Caccamo, A., Oddo, S., Billings, L. M., Green, K. N., Martinez-Coria, H., Fisher, A., \& LaFerla, F. M. (2006). M1 receptors play a central role in modulating AD-like pathology in transgenic mice. Neuron, 49 (5), 671-682.https://doi.org/10.1016/j.neuron.2006.01.020

Cedillo, J. L., Arnalich, F., Martín-Sánchez, C., Quesada, A., Rios, J. J., Maldifassi, M. C., . . Montiel, C. (2015). Usefulness of $\alpha 7$ nicotinic receptor messenger RNA levels in peripheral blood mononuclear cells as a marker for cholinergic antiinflammatory pathway activity in septic patients: results of a pilot study. $J$ Infect Dis, 211 (1), 146-155.https://doi.org/10.1093/infdis/jiu425

Chatterjee, P. K., Al-Abed, Y., Sherry, B., \& Metz, C. N. (2009). Cholinergic agonists regulate JAK2/STAT3 signaling to suppress endothelial cell activation. Am J Physiol Cell Physiol, 297 (5), C12941306.https://doi.org/10.1152/ajpcell.00160.2009

Chaurasia, B., Mauer, J., Koch, L., Goldau, J., Kock, A. S., \& Brüning, J. C. (2010). Phosphoinositidedependent kinase 1 provides negative feedback inhibition to Toll-like receptor-mediated NF-kappaB activation in macrophages. Mol Cell Biol, 30 (17), 4354-4366.https://doi.org/10.1128/mcb.00069-10

Chen, H. W., He, X. H., Yuan, R., Wei, B. J., Chen, Z., Dong, J. X., \& Wang, J. (2016). Sesquiterpenes and a monoterpenoid with acetylcholinesterase (AchE) inhibitory activity from Valeriana officinalis var. latiofolia in vitro and in vivo. Fitoterapia, 110 , 142-149.https://doi.org/10.1016/j.fitote.2016.03.011

Chen, J., Lin, S., \& Zheng, N. (2016). Effect of total flavonoids of litchi on cholinergic antiinflammatory pathway in rats with acute lung injury. Chin J Hosp Pharm, 36 (23), 20512054.https://doi.org/10.13286/j.cnki.chinhosppharmacyj.2016.23.03

Chen, Q., Cao, Y., \& Zhang, C. (2002). Effect of tenuigenin on cholinergic decline induced by $\beta$-amyloid peptide and ibotenic acid in rats. Acta Pharmaceutica Sinica, 37 (12), 913917.https://doi.org/CNKI:SUN:YXXB.0.2002-12-000

Chen, W. (2013). Traditional chinese medicine Fuan and anti-inflammatory pathway for the treatment of postoperative ileus in rat. (Master), Dalian Med Univ, Available from Cnki

Choi, R. J., Roy, A., Jung, H. J., Ali, M. Y., Min, B. S., Park, C. H., . . . Jung, H. A. (2016). BACE1 molecular docking and anti-Alzheimer's disease activities of ginsenosides. J Ethnopharmacol, 190 , 219230.https://doi.org/10.1016/j.jep.2016.06.013

Choo, C. Y., Hirasawa, Y., Karimata, C., Koyama, K., Sekiguchi, M., Kobayashi, J., \& Morita, H. (2007). Carinatumins A-C, new alkaloids from Lycopodium carinatum inhibiting acetylcholinesterase. Bioorg Med 
Chem, 15 (4), 1703-1707.https://doi.org/10.1016/j.bmc.2006.12.005

Cui, R. (2012). Correlation researches between protection of Scutellaria baicalensis Georgi and Coptis Chinensis Franch on rat's acute lung injury and cholinergic anti-inflammatory pathway. (Master), Chengdu Univ Trad Chin Med, Available from Cnki

Cui, R., Meng, X., Wang, P., Li, H., \& Yu, Y. (2012). Correlation between protection of Scutellaria baicalensis extract on rats' acute lung injury and cholinergic anti-inflammatory pathway. Chin Trad Herb Drug, 43 (02), 321-326.https://doi.org/10.7501/j.issn.0253-2670

Dajas-Bailador, F., \& Wonnacott, S. (2004). Nicotinic acetylcholine receptors and the regulation of neuronal signalling. Trends in pharmacological sciences, 25 (6), 317-324.https://doi.org/10.1016/j.tips.2004.04.006

de Git, K. C., \& Adan, R. A. (2015). Leptin resistance in diet-induced obesity: the role of hypothalamic inflammation. Obes Rev, 16 (3), 207-224.https://doi.org/10.1111/obr.12243

de Jonge, W. J., van der Zanden, E. P., The, F. O., Bijlsma, M. F., van Westerloo, D. J., Bennink, R. J., . . . Boeckxstaens, G. E. (2005). Stimulation of the vagus nerve attenuates macrophage activation by activating the Jak2-STAT3 signaling pathway. Nat Immunol, 6 (8), 844-851.https://doi.org/10.1038/ni1229

de Luca, C., \& Olefsky, J. M. (2008). Inflammation and insulin resistance. FEBS Lett, 582 (1), 97105.https://doi.org/10.1016/j.febslet.200\%.11.057

De Rosa, M. J., Dionisio, L., Agriello, E., Bouzat, C., \& Esandi Mdel, C. (2009). Alpha 7 nicotinic acetylcholine receptor modulates lymphocyte activation. Life Sci, 85 (11-12), 444449.https://doi.org/10.1016/j.lfs.2009.0\%.010

Ding, D., Jiao, L., Wang, X., Liu, Z., Fan, L., \& Li, Q. (2018). Influence of breviscapine on myocardial apoptosis and NF-kB pathway signaling molecules $(\alpha 7 \mathrm{nAChR}, \mathrm{p} 65$ and IkB- $\alpha$ ) in rats with myocardial ischemiareperfusion injury. Chin J Evid-Base Card Med, 10 (12), 1480-1483.https://doi.org/10.3969/j.issn.16744055.2018.12.11

Dong, H., Wang, J., Zheng, H., Hua, J., Zhou, L., Liu, L., . . . Guo, Z. (2019). Effects of Naosuikang on spatial memory of VCI rats. Trad Chin Drug Res Clin Pharm, 30 (12), 14741478.https://doi.org/10.19378/j.issn.1003-9783.2019.12.011

Dong, X., Fu, J., Yin, X., Cao, S., Li, X., Lin, L., \& Ni, J. (2016). Emodin: A Review of its Pharmacology, Toxicity and Pharmacokinetics.Phytother Res, 30 (8), 1207-1218.https://doi.org/10.1002/ptr.5631

Dong, Y., Liu, G., Zhang, L., \& Tang, L. (2019). Neuroprotective effect of emodin on acute brain injury in sepsis mice. Med J Chin Peopl Lib Army, 44 (1), 13-19.https://doi.org/10.11855/j.issn.05777402.2019.01.03

Endo, M., Hori, M., Mihara, T., Ozaki, H., Oikawa, T., Odaguchi, H., \& Hanawa, T. (2017). Zingiberis Siccatum Rhizoma, the active component of the Kampo formula Daikenchuto, induces antiinflammatory actions through $\alpha 7$ nicotinic acetylcholine receptor activation. Neurogastroenterol Motil, 29 (12).https://doi.org/10.1111/nmo.13139

Endo, M., Hori, M., Ozaki, H., Oikawa, T., Odaguchi, H., \& Hanawa, T. (2018). Possible anti-inflammatory role of Zingiberis processum rhizoma, one component of the Kampo formula daikenchuto, against neutrophil infiltration through muscarinic acetylcholine receptor activation.J Pharmacol Sci, 137 (4), 379386.https://doi.org/10.1016/j.jphs.2018.08.001

Fan, H., Duan, M., \& Sun, Y. (2019). Protective effect of K receptor agonists on cognitive impairment after operation through MAPK-ERK1/2 pathway. Chin J Med Off, 47 (2), 131133.https://doi.org/10.16680/j.1671-3826.2019.02.07

Farsalinos, K., Niaura, R., Le Houezec, J., Barbouni, A., Tsatsakis, A., Kouretas, D., . . . Poulas, K. (2020). Editorial: Nicotine and SARS-CoV-2: COVID-19 may be a disease of the nicotinic cholinergic 
system. Toxicol Rep, 7, 658-663.https://doi.org/10.1016/j.toxrep.2020.04.012

Feldmann, M., Andreakos, E., Smith, C., Bondeson, J., Yoshimura, S., Kiriakidis, S., . . . Foxwell, B. M. (2002). Is NF-kappaB a useful therapeutic target in rheumatoid arthritis? Ann Rheum Dis, 61 Suppl 2 (Suppl 2), ii13-18.https://doi.org/10.1136/ard.61.suppl_2.ii13

Feng, L., Gong, J., Jin, Z. Y., Li, N., Sun, L. P., Wu, Y. L., \& Pu, J. L. (2009). Electrophysiological effects of Chinese medicine Shen song Yang xin (SSYX) on Chinese miniature swine heart and isolated guinea pig ventricular myocytes. Chin Med J (Engl), 122 (13), 1539-1543.

Fernández-Cabezudo, M. J., George, J. A., Bashir, G., Mohamed, Y. A., Al-Mansori, A., Qureshi, M. M., .. . Al-Ramadi, B. K. (2019). Involvement of Acetylcholine Receptors in Cholinergic Pathway-Mediated Protection Against Autoimmune Diabetes. Front Immunol, 10 , 1038.https://doi.org/10.3389/fimmu.2019.01038

Fujii, Y. X., Tashiro, A., Arimoto, K., Fujigaya, H., Moriwaki, Y., Misawa, H., . . . Kawashima, K. (2007). Diminished antigen-specific IgG1 and interleukin-6 production and acetylcholinesterase expression in combined M1 and M5 muscarinic acetylcholine receptor knockout mice.J Neuroimmunol, 188 (1-2), 80-85.https://doi.org/10.1016/j.jneuroim.2007.05.017

Geng, J., Zhou, A., Hu, Y., Zhu, Y., Mao, J., \& Shi, H. (2008). Effects of Nao Yikang on enzymes of central cholinergic system in rats with Alzheimer 's disease. Lishizhen Med Mater Med Res, 19 (07), 16191621.https://doi.org/10.3969/j.issn.1008-0805.2008.07.034

George, J. A., Bashir, G., Qureshi, M. M., Mohamed, Y. A., Azzi, J., Al-Ramadi, B. K., \& FernándezCabezudo, M. J. (2016). Cholinergic Stimulation Prevents the Development of Autoimmune Diabetes: Evidence for the Modulation of Th17 Effector Cells via an IFN $\gamma$-Dependent Mechanism. Front Immunol, 7 , 419.https://doi.org/10.3389/fimmu.2016.00419

Gotti, C., \& Clementi, F. (2004). Neuronal nicotinic receptors: from structure to pathology. Prog Neurobiol, 74 (6), 363-396.https://doi.org/10.1016/j.pneurobio.2004.09.006

Gu, R., Liu, R., Zhang, L., Hao, X., Xiao, Y., Qi, X., . . . Guan, Z. (2007). Protection of Tianshen Yizhi Recipe against low expression of nicotinic receptor and neurotoxicity induced by $\beta$-amyloid peptide.J Chin Integr Med, 5 (5), 564-569.

Guo, Y., Lip, G. Y., \& Apostolakis, S. (2012). Inflammation in atrial fibrillation. J Am Coll Cardiol, 60 (22), 2263-2270.https://doi.org/10.1016/j.jacc.2012.04.063

Hafizi Abu Bakar, M., Kian Kai, C., Wan Hassan, W. N., Sarmidi, M. R., Yaakob, H., \& Zaman Huri, H. (2015). Mitochondrial dysfunction as a central event for mechanisms underlying insulin resistance: the roles of long chain fatty acids. Diabetes Metab Res Rev, 31 (5), 453-475.https://doi.org/10.1002/dmrr.2601

Hong, Y. (2016). The protection and mechanism of shenfu injection on acute liver injury of sepsis young rats. (Master), Nanchang Univ, Available from Cnki

$\mathrm{Hu}$, J. (2011). Study on regulation of inflammatory response of rats with vascular dementia by bushen Xingnao Prescription. (Doctor), Hunan Univ Trad Chin Med, Available from Cnki

Hu, J., He, Y., Zhang, C., \& Zhao, Q. (2011). Upregulation of vascular endothelial growth factor and downregulation of IL-1 $\beta$,tumor necrosis factor- $\alpha$ by Bushen Xingnao decoction in vascular dementia rats. Chin J Exp Trad Med Form, 17 (5), 190-193.https://doi.org/10.3969/j.issn.1005-9903.2011.05.057

Hu, Y. F., Chen, Y. J., Lin, Y. J., \& Chen, S. A. (2015). Inflammation and the pathogenesis of atrial fibrillation. Nat Rev Cardiol, 12 (4), 230-243.https://doi.org/10.1038/nrcardio.2015.2

Huang, X. (2010). Effects of triptolide on astrocytes and cholinergic fibers after microinjection of beta-amyloid protein into cerebral cortex in rats. (Mater), Nanchang Univ, Available from Cnki 
Hung, T. M., Luan, T. C., Vinh, B. T., Cuong, T. D., \& Min, B. S. (2011). Labdane-type diterpenoids from Leonurus heterophyllus and their cholinesterase inhibitory activity. Phytother Res, 25 (4), 611614.https://doi.org/10.1002/ptr.3307

Huston, J. M., Wang, H., Ochani, M., Ochani, K., Rosas-Ballina, M., Gallowitsch-Puerta, M., . . . Yang, H. (2008). Splenectomy protects against sepsis lethality and reduces serum HMGB1 levels. J Immunol, 181 (5), 3535-3539.https://doi.org/10.4049/jimmunol.181.5.3535

Ide, K., Matsuoka, N., Yamada, H., Furushima, D., \& Kawakami, K. (2018). Effects of Tea Catechins on Alzheimer's Disease: Recent Updates and Perspectives. Molecules, 23 (9).https://doi.org/10.3390/molecules23092357

Jiang, P., Ma, D., Wang, X., Wang, Y., Bi, Y., Yang, J., . . . Li, X. (2018). Astragaloside IV Prevents Obesity-Associated Hypertension by Improving Pro-Inflammatory Reaction and Leptin Resistance. Mol Cells, 41 (3), 244-255.https://doi.org/10.14348/molcells.2018.2156

Jiang, Y., Gao, H., \& Turdu, G. (2017). Traditional Chinese medicinal herbs as potential AChE inhibitors for anti-Alzheimer's disease: A review. Bioorg Chem, 75, 50-61.https://doi.org/10.1016/j.bioorg.2017.09.004

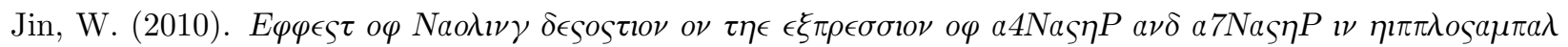

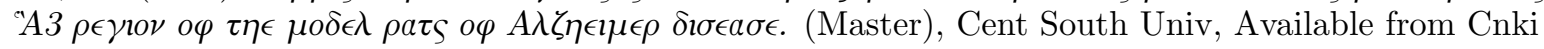

Jin, X., Wang, D., Xie, J., Zhang, L., \& Liu, Q. (2019). Effects of bilobalide on cholinergic neurotransmitters, oxidative stress and inflammation induced by A $1-40$ in AD model rats. J Trad Chin Mater (11), 26932696.https://doi.org/10.13863/j.issn1001-4454.2019.11.041

Kanashiro, A., Sônego, F., Ferreira, R. G., Castanheira, F. V., Leite, C. A., Borges, V. F., . . Cunha, F. Q. (2017). Therapeutic potential and limitations of cholinergic anti-inflammatory pathway in sepsis.Pharmacol Res, 117 , 1-8.https://doi.org/10.1016/j.phrs.2016.12.014

Ke, B., Shen, X. D., Ji, H., Kamo, N., Gao, F., Freitas, M. C., . . Kupiec-Weglinski, J. W. (2012). HO1-STAT3 axis in mouse liver ischemia/reperfusion injury: regulation of TLR4 innate responses through PI3K/PTEN signaling. J Hepatol, 56 (2), 359-366.https://doi.org/10.1016/j.jhep.2011.05.023

Khan, M. R., Islam, M. T., Yazawa, T., Hayashi, H., Suzuki, Y., Uwada, J., . . Taniguchi, T. (2015). Muscarinic cholinoceptor-mediated activation of JNK negatively regulates intestinal secretion in mice.J Pharmacol Sci, 127 (1), 150-153.https://doi.org/10.1016/j.jphs.2014.10.001

Kim, D. K., Lee, K. T., Baek, N. I., Kim, S. H., Park, H. W., Lim, J. P., . . . Eun, J. S. (2004). Acetylcholinesterase inhibitors from the aerial parts of Corydalis speciosa. Arch Pharm Res, 27 (11), 11271131.https://doi.org/10.1007/bf02975117

Kim, T. H., Kim, S. J., \& Lee, S. M. (2014). Stimulation of the $\alpha 7$ nicotinic acetylcholine receptor protects against sepsis by inhibiting Toll-like receptor via phosphoinositide 3-kinase activation. J Infect Dis, 209 (10), 1668-1677.https://doi.org/10.1093/infdis/jit669

Klein, R. L., Wilson, S. P., Dzielak, D. J., Yang, W. H., \& Viveros, O. H. (1982). Opioid peptides and noradrenaline co-exist in large dense-cored vesicles from sympathetic nerve. Neuroscience, 7 (9), 22552261.https://doi.org/10.1016/0306-4522(82)90135-x

Kruse, A. C., Kobilka, B. K., Gautam, D., Sexton, P. M., Christopoulos, A., \& Wess, J. (2014). Muscarinic acetylcholine receptors: novel opportunities for drug development. Nat Rev Drug Discov, 13 (7), 549560.https://doi.org/10.1038/nrd4295

La Joie, R., Visani, A. V., Baker, S. L., Brown, J. A., Bourakova, V., Cha, J., . . Rabinovici, G. D. (2020). Prospective longitudinal atrophy in Alzheimer's disease correlates with the intensity and topography of baseline tau-PET. Sci Transl Med, 12 (524).https://doi.org/10.1126/scitranslmed.aau5732 
Lai, D. H., Yang, Z. D., Xue, W. W., Sheng, J., Shi, Y., \& Yao, X. J. (2013). Isolation, characterization and acetylcholinesterase inhibitory activity of alkaloids from roots of Stemona sessilifolia.Fitoterapia, 89 , 257-264.https://doi.org/10.1016/j.fitote.2013.06.010

Lee, I., Ahn, B., Choi, J., Hattori, M., Min, B., \& Bae, K. (2011). Selective cholinesterase inhibition by lanostane triterpenes from fruiting bodies of Ganoderma lucidum. Bioorg Med Chem Lett, 21 (21), 66036607.https://doi.org/10.1016/j.bmcl.2011.04.042

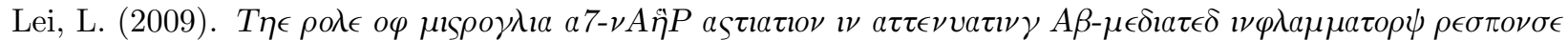

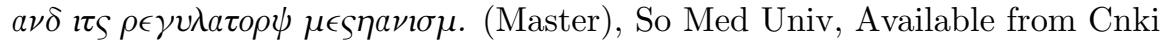

Leung, J. M., Yang, C. X., \& Sin, D. D. (2020). COVID-19 and nicotine as a mediator of ACE-2. Eur Respir J, 55 (6).https://doi.org/10.1183/13993003.01261-2020

Li, D. J., Zhao, T., Xin, R. J., Wang, Y. Y., Fei, Y. B., \& Shen, F. M. (2014). Activation of $\alpha 7$ nicotinic acetylcholine receptor protects against oxidant stress damage through reducing vascular peroxidase-1 in a JNK signaling-dependent manner in endothelial cells. Cell Physiol Biochem, 33 (2), 468-478.https://doi.org/10.1159/000358627

Li, F. (2013). Effects of Rheum officinale Baill, Scutellaria baicalensis Georgi and the compatibility on cholinergic anti-inflammatory pathway through PK/PD method. (Master), Chengdu Univ Trad Chin Med, Available from Cnki

Li, F., Zhao, Y. B., Wang, D. K., Zou, X., Fang, K., \& Wang, K. F. (2016). Berberine relieves insulin resistance via the cholinergic anti-inflammatory pathway in HepG2 cells. J Huazhong Univ Sci Technolog Med Sci, 36 (1), 64-69.https://doi.org/10.1007/s11596-016-1543-5

Li, P., Liu, S., Liu, Q., Shen, J., Yang, R., Jiang, B., . . . Xiao, P. (2019). Screening of acetylcholinesterase inhibitors and characterizing of phytochemical constituents from Dichocarpum auriculatum (Franch.) W.T. Wang \& P. K. Hsiao through UPLC-MS combined with an acetylcholinesterase inhibition assay in vitro. $J$ Ethnopharmacol, 245, 112185.https://doi.org/10.1016/j.jep.2019.112185

$\mathrm{Li}, \mathrm{Q}$. (2011). The mechanism of miR-124a in the cholinergic anti-inflammatory pathway. (Doctor), Second Mil Med Univ, Available from Cnki

Li, Y. X., Han, T. T., Liu, Y., Zheng, S., Zhang, Y., Liu, W., \& Hu, Y. M. (2015). Insulin resistance caused by lipotoxicity is related to oxidative stress and endoplasmic reticulum stress in LPL gene knockout heterozygous mice. Atherosclerosis, 239 (1), 276-282.https://doi.org/10.1016/j.atherosclerosis.2015.01.020

Li, Z., Hao, H., Gao, Y., Wang, Z., Lu, W., \& Liu, J. (2019). Expression and localization analyses of the cholinergic anti-inflammatory pathway and $\alpha 7 \mathrm{nAchR}$ in different tissues of rats with rheumatoid arthritis. Acta Histochem, 121 (6), 742-749.https://doi.org/10.1016/j.acthis.2019.0\%.001

Liu, F., Li, Y., Jiang, R., Nie, C., Zeng, Z., Zhao, N., . . . Qian, K. (2015). miR-132 inhibits lipopolysaccharide-induced inflammation in alveolar macrophages by the cholinergic anti-inflammatory pathway.Exp Lung Res, 41 (5), 261-269.https://doi.org/10.3109/01902148.2015.1004206

Liu, J. S., Wei, X. D., Lu, Z. B., Xie, P., Zhou, H. L., Chen, Y. Y., . . . Yu, L. Z. (2016). Liang-Ge-San, a classic traditional Chinese medicine formula, protects against lipopolysaccharide-induced inflammation through cholinergic anti-inflammatory pathway. Oncotarget, 7 (16), 21222-21234.https://doi.org/10.18632/oncotarget.8452

Liu, L., Chen, S., Xu, X., Hou, B., \& Mo, F. (2017). Astragalus polysaccharides combined with ibuprofen exhibit a therapeutic effect on septic rats via an anti-inflammatory cholinergic pathway. Exp Ther Med, 14 (4), 3127-3130.https://doi.org/10.3892/etm.2017.4865

Liu, W., \& Zhang, Y. (2019). Effects of tripterygium glycosides on fibroblast-Like synoviocyte $\alpha 7$ nicotinic acetylcholine receptor and inflammatory factors in patients with rheumatoid arthritis.Shandong J Trad Chin 
Med, 38 (12), 1166-1170.https://doi.org/10.16295/j.cnki.0257-358x.2019.12.017

Liu, Y., Li, S., \& Zheng, Q. (2012). Effects of Bushen Jiannao Recipe on the content of acetylocholine and the hipppcampal ERK1 and ERK2 protein expressions of vascular dementia rats. Chin J Integr Trad West Med, 32 (4), 504-509.https://doi.org/10.7661/CJIM.2012.4.504

Liu, Y., Song, B., Li, Z., Jiang, B., \& Pan, R. (2012). Research on cholinesterase inhibitory action and chemical constituents in the volatile oil of radix peucedani. Nat Prod Res Dev, 24 (11), 1620.https://doi.org/10.3969/j.issn.1001-6880.2012.11.003

Liu, Y., Wu, D., Song, F., Zhu, C., Hui, Y., Zhu, Q., . . . Hu, J. (2015). Activation of $\alpha 7$ nicotinic acetylcholine receptors prevents monosodium iodoacetate-induced osteoarthritis in rats. Cell Physiol Biochem, 35 (2), 627-638.https://doi.org/10.1159/000369724

Lou, T., Zhang, Z., Xi, Z., Liu, K., Li, L., Liu, B., \& Huang, F. (2011). Berberine inhibits inflammatory response and ameliorates insulin resistance in hepatocytes. Inflammation, 34 (6), 659667.https://doi.org/10.1007/s10753-010-9276-2

Lu, Z., Xie, P., Zhang, D., Sun, P., Yang, H., Ye, J., . . . Liu, J. (2018). 3-Dehydroandrographolide protects against lipopolysaccharide-induced inflammation through the cholinergic anti-inflammatory pathway. Biochem Pharmacol, 158 , 305-317.https://doi.org/10.1016/j.bcp.2018.10.034

Ma, W., Ma, F., Miao, Z., Ma, L., \& Tian, J. (2008). Study on the protective effect of CSF containing LDD components on the AD model with deficits of $\alpha 7 n A C h R$ induced by A $\mu 1-40$. Ningxia Med J, 30 (4), 289-291.https://doi.org/10.3969/j.issn.1001-5949.2008.04.001

Makarov, S. S. (2001). NF-kappa B in rheumatoid arthritis: a pivotal regulator of inflammation, hyperplasia, and tissue destruction.Arthritis Res, 3 (4), 200-206.https://doi.org/10.1186/ar300

Mao, X., Miao, G., Wu, X., \& Chen, Z. (2014). Effect of total flavone of Hawthorn leaves on activity of learning and memory and AChE and ChAT in brian of vascular dementia rat model. Chin J Exp Trad Med Form, 20 (17), 167-170.https://doi.org/10.13422/j.cnki.syfjx.2014170167

Mark, A. L. (2013). Selective leptin resistance revisited. Am J Physiol Regul Integr Comp Physiol, 305 (6), R566-581.https://doi.org/10.1152/ajpregu.00180.2013

Marrero, M. B., \& Bencherif, M. (2009). Convergence of alpha 7 nicotinic acetylcholine receptor-activated pathways for anti-apoptosis and anti-inflammation: central role for JAK2 activation of STAT3 and NFkappaB. Brain Res, 1256 , 1-7.https://doi.org/10.1016/j.brainres.2008.11.053

Marrero, M. B., Lucas, R., Salet, C., Hauser, T. A., Mazurov, A., Lippiello, P. M., \& Bencherif, M. (2010). An alpha7 nicotinic acetylcholine receptor-selective agonist reduces weight gain and metabolic changes in a mouse model of diabetes. J Pharmacol Exp Ther, 332 (1), 173-180.https://doi.org/10.1124/jpet.109.154633

Mousavi, M., \& Hellström-Lindahl, E. (2009). Nicotinic receptor agonists and antagonists increase sAPPalpha secretion and decrease Abeta levels in vitro. Neurochem Int, 54 (3-4), 237244.https://doi.org/10.1016/j.neuint.2008.12.001

$\mathrm{Mu}$, J., \& Li, X. (2007). Effect of Yuanzhi on learning and memory and AchE activity of model rats with Alzheimer's disease. World J Integr Trad West Med, 2 (01), 1820.https://doi.org/10.13935/j.cnki.sjzx.2007.01.009

Muthu, K., He, L. K., Szilagyi, A., Strotmon, P., Gamelli, R. L., \& Shankar, R. (2010). B-adrenergic stimulation increases macrophage CD14 expression and E. coli phagocytosis through PKA signaling mechanisms. $J$ Leukoc Biol, 88 (4), 715-724.https://doi.org/10.1189/jlb.0410186

Nance, D. M., \& Sanders, V. M. (2007). Autonomic innervation and regulation of the immune system (19872007). Brain Behav Immun, 21 (6), 736-745.https://doi.org/10.1016/j.bbi.2007.03.008 
Nezhinskaia, G. I., Vladykin, A. L., \& Sapronov, N. S. (2010). Anti-inflammatory role of cholinergic and serotonergic systems in shock.Patol Fiziol Eksp Ter (2), 7-10.

Nitsch, R. M., Slack, B. E., Wurtman, R. J., \& Growdon, J. H. (1992). Release of Alzheimer amyloid precursor derivatives stimulated by activation of muscarinic acetylcholine receptors. Science, 258 (5080), 304-307.https://doi.org/10.1126/science.1411529

Okello, E. J., \& Mather, J. (2020). Comparative Kinetics of Acetyl- and Butyryl-Cholinesterase Inhibition by Green Tea Catechins|Relevance to the Symptomatic Treatment of Alzheimer's Disease. Nutrients, 12 (4).https://doi.org/10.3390/nu12041090

Pappas, B. A., Bayley, P. J., Bui, B. K., Hansen, L. A., \& Thal, L. J. (2000). Choline acetyltransferase activity and cognitive domain scores of Alzheimer's patients. Neurobiol Aging, 21 (1), 1117.https://doi.org/10.1016/s0197-4580(00)00090-7

Pavlov, V. A., Ochani, M., Gallowitsch-Puerta, M., Ochani, K., Huston, J. M., Czura, C. J., . . Tracey, K. J. (2006). Central muscarinic cholinergic regulation of the systemic inflammatory response during endotoxemia. Proc Natl Acad Sci U S A, 103 (13), 5219-5223.https://doi.org/10.1073/pnas.0600506103

Pavlov, V. A., \& Tracey, K. J. (2006). Controlling inflammation: the cholinergic anti-inflammatory pathway. Biochem Soc Trans, 34 (Pt 6), 1037-1040.https://doi.org/10.1042/bst0341037

Peña, G., Cai, B., Liu, J., van der Zanden, E. P., Deitch, E. A., de Jonge, W. J., \& Ulloa, L. (2010). Unphosphorylated STAT3 modulates alpha 7 nicotinic receptor signaling and cytokine production in sepsis.Eur $J$ Immunol, 40 (9), 2580-2589.https://doi.org/10.1002/eji.201040540

Peng, X. R., Liu, J. Q., Wan, L. S., Li, X. N., Yan, Y. X., \& Qiu, M. H. (2014). Four new polycyclic meroterpenoids from Ganoderma cochlear.Org Lett, 16 (20), 5262-5265.https://doi.org/10.1021/ol5023189

Pereira, M. R., \& Leite, P. E. (2016). The Involvement of Parasympathetic and Sympathetic Nerve in the Inflammatory Reflex.J Cell Physiol, 231 (9), 1862-1869.https://doi.org/10.1002/jcp.25307

Perry, E. K. (1986). The cholinergic hypothesis-ten years on.Br Med Bull, 42 (1), 6369.https://doi.org/10.1093/oxfordjournals.bmb.a072100

Qin, Z., Wang, P. Y., Su, D. F., \& Liu, X. (2016). miRNA-124 in Immune System and Immune Disorders. Front Immunol, 7 , 406.https://doi.org/10.3389/fimmu.2016.00406

Ren, M., Wang, Y., Zhang, C., Li, Y., Wang, Y., \& Miao, Z. (2016). Effect of Lycium Barbarum Polysaccharide on the Inflammatory Response and the Expression of $\alpha 7 \mathrm{nAChR}$ on the Astrocytes Activated by A $\beta$. J Ningxia Med Univ, 38 (5), 502-507.https://doi.org/10.16050/j.cnki.issn1674-6309.2016.05.006

Rosas-Ballina, M., Ochani, M., Parrish, W. R., Ochani, K., Harris, Y. T., Huston, J. M., . . . Tracey, K. J. (2008). Splenic nerve is required for cholinergic antiinflammatory pathway control of TNF in endotoxemia.Proc Natl Acad Sci U S A, 105 (31), 11008-11013.https://doi.org/10.1073/pnas.0803237105

Rosas-Ballina, M., Olofsson, P. S., Ochani, M., Valdés-Ferrer, S. I., Levine, Y. A., Reardon, C., . . Tracey, K. J. (2011). Acetylcholine-synthesizing T cells relay neural signals in a vagus nerve circuit. Science, 334 (6052), 98-101.https://doi.org/10.1126/science.1209985

Russo, P., Bonassi, S., Giacconi, R., Malavolta, M., Tomino, C., \& Maggi, F. (2020). COVID-19 and smoking: is nicotine the hidden link? Eur Respir J, 55 (6).https://doi.org/10.1183/13993003.01116-2020

Samochocki, M., Höflle, A., Fehrenbacher, A., Jostock, R., Ludwig, J., Christner, C., . . Maelicke, A. (2003). Galantamine is an allosterically potentiating ligand of neuronal nicotinic but not of muscarinic acetylcholine receptors. J Pharmacol Exp Ther, 305 (3), 1024-1036.https://doi.org/10.1124/jpet.102.045773

Samuel, I., Zaheer, S., Fisher, R. A., \& Zaheer, A. (2003). Cholinergic receptor induction and JNK activation in acute pancreatitis. Am J Surg, 186 (5), 569-574.https://doi.org/10.1016/j.amjsurg.2003.07.016 
Seo, W. D., Kim, J. Y., Ryu, H. W., Kim, J. H., Han, S.-I., Ra, J.-E., . . Lee, J. H. (2013). Identification and characterisation of coumarins from the roots of Angelica dahurica and their inhibitory effects against cholinesterase. J Journal of Functional Foods, 5 (3), 1421-1431.

Severn, A., Rapson, N. T., Hunter, C. A., \& Liew, F. Y. (1992). Regulation of tumor necrosis factor production by adrenaline and beta-adrenergic agonists. J Immunol, 148 (11), 3441-3445.

Shang, L. L., Sanyal, S., Pfahnl, A. E., Jiao, Z., Allen, J., Liu, H., \& Dudley, S. C., Jr. (2008). NF-kappaBdependent transcriptional regulation of the cardiac scn5a sodium channel by angiotensin II.Am J Physiol Cell Physiol, 294 (1), C372-379.https://doi.org/10.1152/ajpcell.00186.2007

Shaw, S., Bencherif, M., \& Marrero, M. B. (2002). Janus kinase 2, an early target of alpha 7 nicotinic acetylcholine receptor-mediated neuroprotection against Abeta-(1-42) amyloid. J Biol Chem, 277 (47), 4492044924.https://doi.org/10.1074/jbc.M204610200

Shi, D., Wang, J., \& Liu, W. (2011). The acetylcholinesterase -inhibition activities of extracts of traditional chinese medicine.Lishizhen Med Mat Medi Res, 22 (1), 62-64.https://doi.org/10.3969/j.issn.10080805.2011.01.024

Singer, M., Deutschman, C. S., Seymour, C. W., Shankar-Hari, M., Annane, D., Bauer, M., . . Angus, D. C. (2016). The Third International Consensus Definitions for Sepsis and Septic Shock (Sepsis-3).Jama, 315 (8), 801-810.https://doi.org/10.1001/jama.2016.0287

Song, J., Wang, H., Si, N., \& Bian, B. (2010). Antioxidant activity and inhibition on acetylcholinesterase by Huanglianjiedu decoction. Chin J Exp Trad Med Form, 16 (5), 61-64.https://doi.org/10.3969/j.issn.10059903.2010.05.019

Song, X. M., Li, J. G., Wang, Y. L., Hu, Z. F., Zhou, Q., Du, Z. H., \& Jia, B. H. (2008). The protective effect of the cholinergic anti-inflammatory pathway against septic shock in rats. Shock, 30 (4), 468472.https://doi.org/10.1097/SHK.0b013e31816d5e49

Spranger, J., Kroke, A., Möhlig, M., Hoffmann, K., Bergmann, M. M., Ristow, M., . . Pfeiffer, A. F. (2003). Inflammatory cytokines and the risk to develop type 2 diabetes: results of the prospective population-based European Prospective Investigation into Cancer and Nutrition (EPIC)-Potsdam Study. Diabetes, 52 (3), 812-817.https://doi.org/10.2337/diabetes.52.3.812

$\mathrm{Su}$, X., Matthay, M. A., \& Malik, A. B. (2010). Requisite role of the cholinergic alpha7 nicotinic acetylcholine receptor pathway in suppressing Gram-negative sepsis-induced acute lung inflammatory injury. $J$ Immunol, 184 (1), 401-410.https://doi.org/10.4049/jimmunol.0901808

Sun, P., Zhou, K., Wang, S., Li, P., Chen, S., Lin, G., . . Wang, T. (2013). Involvement of MAPK/NF- $x$ B signaling in the activation of the cholinergic anti-inflammatory pathway in experimental colitis by chronic vagus nerve stimulation. PLoS One, 8 (8), e69424.https://doi.org/10.1371/journal.pone.0069424

Sun, W., Miao, Z., Wang, Y., Qin, J., \& Chen, J. (2010). Effects of Ningxia wolfberry whole fruit on cognition of natural aging mice and expression of $\alpha 7 \mathrm{nAChR}$ in brain tissue. Shandong Med J, 50 (30), 31-33.https://doi.org/10.3969/j.issn.1002-266X.2010.30.017

Sun, Y., Li, Q., Gui, H., Xu, D. P., Yang, Y. L., Su, D. F., \& Liu, X. (2013). MicroRNA-124 mediates the cholinergic anti-inflammatory action through inhibiting the production of pro-inflammatory cytokines. Cell Res, 23 (11), 1270-1283.https://doi.org/10.1038/cr.2013.116

Swarup, V., Ghosh, J., Mishra, M. K., \& Basu, A. (2008). Novel strategy for treatment of Japanese encephalitis using arctigenin, a plant lignan.J Antimicrob Chemother, 61 (3), 679688.https://doi.org/10.1093/jac/dkm503

Takada-Takatori, Y., Kume, T., Izumi, Y., Ohgi, Y., Niidome, T., Fujii, T., . . . Akaike, A. (2009). Roles of nicotinic receptors in acetylcholinesterase inhibitor-induced neuroprotection and nicotinic receptor 
up-regulation. Biol Pharm Bull, 32 (3), 318-324.https://doi.org/10.1248/bpb.32.318

Tasaka, Y., Yasunaga, D., Kiyoi, T., Tanaka, M., Tanaka, A., Suemaru, K., \& Araki, H. (2015). Involvement of stimulation of $\alpha 7$ nicotinic acetylcholine receptors in the suppressive effect of tropisetron on dextran sulfate sodium-induced colitis in mice. J Pharmacol Sci, 127 (3), 275283.https://doi.org/10.1016/j.jphs.2014.12.016

Tian, L. (2009). Influence of Mailuoning on cholinergic receptor expression of temporal cortex in early Alzheimer's disease rat model.(Master), Hebei Med Univ, Available from Cnki

Tohgi, H., Abe, T., Hashiguchi, K., Saheki, M., \& Takahashi, S. (1994). Remarkable reduction in acetylcholine concentration in the cerebrospinal fluid from patients with Alzheimer type dementia. Neurosci Lett, 177 (1-2), 139-142.https://doi.org/10.1016/0304-3940(94)90064-7

Tracey, K. J. (2002). The inflammatory reflex. Nature, 420 (6917), 853859.https://doi.org/10.1038/nature01321

Tracey, K. J. (2009). Reflex control of immunity. Nat Rev Immunol, 9 (6), 418428.https://doi.org/10.1038/nri2566

Tsang, S. W., Lai, M. K., Kirvell, S., Francis, P. T., Esiri, M. M., Hope, T., . . . Wong, P. T. (2006). Impaired coupling of muscarinic M1 receptors to G-proteins in the neocortex is associated with severity of dementia in Alzheimer's disease. Neurobiol Aging, 27 (9), 12161223.https://doi.org/10.1016/j.neurobiolaging.2005.07.010

Ulloa, L. (2005). The vagus nerve and the nicotinic anti-inflammatory pathway. Nat Rev Drug Discov, 4 (8), 673-684.https://doi.org/10.1038/nrd1797

Ulloa, L. (2013). The cholinergic anti-inflammatory pathway meets microRNA. Cell Res, 23 (11), 12491250.https://doi.org/10.1038/cr.2013.128

van Maanen, M. A., Lebre, M. C., van der Poll, T., LaRosa, G. J., Elbaum, D., Vervoordeldonk, M. J., \& Tak, P. P. (2009). Stimulation of nicotinic acetylcholine receptors attenuates collagen-induced arthritis in mice. Arthritis Rheum, 60 (1), 114-122.https://doi.org/10.1002/art.24177

Vida, G., Peña, G., Kanashiro, A., Thompson-Bonilla Mdel, R., Palange, D., Deitch, E. A., \& Ulloa, L. (2011). $\beta 2$-Adrenoreceptors of regulatory lymphocytes are essential for vagal neuromodulation of the innate immune system. Faseb j, 25 (12), 4476-4485.https://doi.org/10.1096/fj.11-191007

Wallace, W., \& Donnelly, S. C. (2002). Pathogenesis of acute microvascular lung injury and the acute respiratory distress syndrome. In T. W. Evans, M. J. D. Griffiths, \& B. F. Keogh (Eds.), ARDS European Respiratory Society Monograph (pp. 22-32): European Respiratory Society.

Wang, H., Zhao, S., Yue, Q. a., Yan, L., Gong, Y., Ji, R., . . . Qian, Z. (2007). Study of the Effect of Daicong Solution on Gene Expression of M1 ,M3 Receptor in Aged Rat Dementia Model. Acta acad med weifang (05), 392-393+481.https://doi.org/10.3969/j.issn.1004-3101.2007.05.004

Wang, H. Y., Bakshi, K., Shen, C., Frankfurt, M., Trocmé-Thibierge, C., \& Morain, P. (2010). S 24795 limits beta-amyloid-alpha7 nicotinic receptor interaction and reduces Alzheimer's disease-like pathologies. Biol Psychiatry, 67 (6), 522-530.https://doi.org/10.1016/j.biopsych.2009.09.031

Wang, M., Mei, Z., Zeng, Y., \& Liu, X. (2012). Puerarin inhibits cerebral ischemia-reperfusion injury in rats by activating cholinergic anti-inflammatory pathway. Chin J Gerontol, 32 (12), 25632566.https://doi.org/10.3969/j.issn.1005-9202.2012.12.054

Wang, Q., \& Li, X. K. (2011). Immunosuppressive and anti-inflammatory activities of sinomenine. Int Immunopharmacol, 11 (3), 373-376.https://doi.org/10.1016/j.intimp.2010.11.018 
Wang, Q., \& Zhou, H. (2011). Effect of amyloid beta on astrocytes in Alzheimer's disease. Chin J Geronol, 31 (18), 3643-3646.https://doi.org/10.3969/j.issn.1005-9202.2011.18.104

Wang, X., Ge, A., Cheng, M., Guo, F., Zhao, M., Zhou, X., . . Yang, N. (2012). Increased hypothalamic inflammation associated with the susceptibility to obesity in rats exposed to high-fat diet. Exp Diabetes Res, 2012, 847246.https://doi.org/10.1155/2012/847246

Wang, X. L., Deng, Y. X., Gao, Y. M., Dong, Y. T., Wang, F., Guan, Z. Z., . . Qi, X. L. (2020). Activation of $\alpha 7 \mathrm{nAChR}$ by PNU-282987 improves synaptic and cognitive functions through restoring the expression of synaptic-associated proteins and the CaM-CaMKII-CREB signaling pathway. Aging (Albany NY), 12 (1), 543-570.https://doi.org/10.18632/aging.102640

Williams, D. L., Li, C., Ha, T., Ozment-Skelton, T., Kalbfleisch, J. H., Preiszner, J., . . . Schweitzer, J. B. (2004). Modulation of the phosphoinositide 3-kinase pathway alters innate resistance to polymicrobial sepsis. J Immunol, 172 (1), 449-456.https://doi.org/10.4049/jimmunol.172.1.449

Wu, H., Li, L., \& Su, X. (2014). Vagus nerve through $\alpha 7 \mathrm{nAChR}$ modulates lung infection and inflammation: models, cells, and signals.Biomed Res Int, 2014, 283525.https://doi.org/10.1155/2014/283525

Xia, Z., Peng, W., Cheng, S., Zhong, B., Sheng, C., Zhang, C., . . . Wang, Z. (2017). Naoling decoction restores cognitive function by inhibiting the neuroinflammatory network in a rat model of Alzheimer's disease. Oncotarget, 8 (26), 42648-42663.https://doi.org/10.18632/oncotarget.17337

Xiang, J., Yu, C., Yang, F., Yang, L., \& Ding, H. (2009). Conformation-activity studies on the interaction of berberine with acetylcholinesterase: Physical chemistry approach. Progress in Natural Science, 19 , 1721-1725.https://doi.org/10.1016/j.pnsc.2009.07.010

Xiao, Y., Zeng, Y., Ouyang, H., Cheng, H., \& Chen, Q. (2013). The effect of the Rhizoma Polygonati and Earth Worm mixtures on cognitive ability and cholinergic system of Alzheimer's disease in rats.Pharm Clin Chin Mat Med, 29 (4), 146-148.

Xiao, Y. T., Wang, J., Lu, W., Cao, Y., \& Cai, W. (2016). Downregulated expression of microRNA-124 in pediatric intestinal failure patients modulates macrophages activation by inhibiting STAT3 and AChE. Cell Death Dis, 7 (12), e2521.https://doi.org/10.1038/cddis.2016.426

Xin, Z., Euikyung, K., Tian, Z., Lin, G., \& Guo, Y. J. C. S. B. (2001). Icariin on relaxation effect ofrncorpus cavernosum smoothrnmuscle. Chin Sci Bull, 046 (014), 1186-1191.

Xing, J., Jiang, P., Jiang, Y., Pang, A., Mou, L., Niang, Z., . . . Qin, L. (2018). Effects of Hebi Recipe on the expression of $\alpha 7 \mathrm{nAChR}$, STAT3 protein and the expression of TNF- $\alpha$, IL-6, IL-17 on rheumatoid arthritis rats. Chin J Trad Chin Med Pharm, 33 (2), 730-733.

Xu, D., Lv, Y., Wang, J., Yang, M., \& Kong, L. (2017). Deciphering the mechanism of Huang-LianJie-Du-Decoction on the treatment of sepsis by formula decomposition and metabolomics: Enhancement of cholinergic pathways and inhibition of HMGB-1/TLR4/NF- $x \mathrm{~B}$ signaling. Pharmacol Res, 121 , 94113.https://doi.org/10.1016/j.phrs.2017.04.016

Xu, H., Turnquist, H. R., Hoffman, R., \& Billiar, T. R. (2017). Role of the IL-33-ST2 axis in sepsis. Mil Med Res, 4, 3.https://doi.org/10.1186/s40779-017-0115-8

Xue, P., Huang, z., ZHang, H., Xia, Q., Li, Y., Wang, Z., . . . Guo, J. (2006). Impact of Chai qin cheng qi decoction on cholinergic anti-inflammatory pathway in rats with severe acute pancreatitis. J Sichuan Univ (Med Sci Edi), 37 (1), 66-68.https://doi.org/10.3969/j.issn.1672-173X.2006.01.018

Yang, L., Zhao, J., Wang, S., Wang, J., \& Wang, Y. (2020). Dangshen Yuanzhi Powder microemulsion attenuates learning and memory impairment in Alzheimer's disease model mice. Chin Trad Herb Drug, 51 (5), 1257-1263.https://doi.org/10.7501/j.issn.0253-2670.2020.05.023 
Yang, Z. D., Duan, D. Z., Du, J., Yang, M. J., Li, S., \& Yao, X. J. (2012). Geissoschizine methyl ether, a corynanthean-type indole alkaloid from Uncaria rhynchophylla as a potential acetylcholinesterase inhibitor. Nat Prod Res, 26 (1), 22-28.https://doi.org/10.1080/14786419.2010.529811

Yao, R. B., Zhao, Z. M., Zhao, L. J., \& Cai, H. (2017). Sinomenine inhibits the inflammatory responses of human fibroblast-like synoviocytes via the TLR4/MyD88/NF- $\varkappa \mathrm{B}$ signaling pathway in rheumatoid arthritis. Pharmazie, 72 (6), 355-360.https://doi.org/10.1691/ph.2017.6946

Yi, L., Luo, J. F., Xie, B. B., Liu, J. X., Wang, J. Y., Liu, L., . . . Dong, Y. (2015). a7 Nicotinic Acetylcholine Receptor is a Novel Mediator of Sinomenine Anti-Inflammation Effect in Macrophages Stimulated by Lipopolysaccharide. Shock, 44 (2), 188-195.https://doi.org/10.1097/shk.0000000000000389

Yi, L., Lyn, Y. J., Peng, C., Zhu, R. L., Bai, S. S., Liu, L., . . . Dong, Y. (2018). Sinomenine inhibits fibroblast-like synoviocyte proliferation by regulating $\alpha 7 \mathrm{nAChR}$ expression via ERK/Egr-1 pathway.Int Immunopharmacol, 56 , 65-70.https://doi.org/10.1016/j.intimp.2018.01.015

Yoshikawa, H., Kurokawa, M., Ozaki, N., Nara, K., Atou, K., Takada, E., . . . Suzuki, N. (2006). Nicotine inhibits the production of proinflammatory mediators in human monocytes by suppression of I-kappaB phosphorylation and nuclear factor-kappaB transcriptional activity through nicotinic acetylcholine receptor alpha7. Clin Exp Immunol, 146 (1), 116-123.https://doi.org/10.1111/j.1365-2249.2006.03169.x

You, Z. (2007). Impact of Chai qin cheng qi decoction on cholinergic anti-inflammatory pathway in rats with severe acute pancreatitis. (Master), Sichuan Univ, Available from Cnki

Yu, Z., Zhang, W., \& Kone, B. C. (2002). Signal transducers and activators of transcription 3 (STAT3) inhibits transcription of the inducible nitric oxide synthase gene by interacting with nuclear factor kappaB. Biochem J, 367 (Pt 1), 97-105.https://doi.org/10.1042/bj20020588

Yue, M., Zhang, X., Dou, Y., Wei, Z., Tao, Y., Xia, Y., \& Dai, Y. (2018). Gut-Sourced Vasoactive Intestinal Polypeptide Induced by the Activation of $\alpha 7$ Nicotinic Acetylcholine Receptor Substantially Contributes to the Anti-inflammatory Effect of Sinomenine in Collagen-Induced Arthritis. Front Pharmacol, 9 , 675.https://doi.org/10.3389/fphar.2018.00675

Zabrodskii, P. F., Lim, V. G., Shekhter, M. S., \& Kuzmin, A. V. (2012). Role of nicotinic and muscarinic cholinoreceptors in the realization of the cholinergic anti-inflammatory pathway during the early phase of sepsis. Bull Exp Biol Med, 153 (5), 700-703.https://doi.org/10.1007/s10517-012-1803-8

Zeng, H., Deng, B., Yan, J., Liu, Y., \& Tang, B. (2009). Effect of saponins of polygala on learning, memory and activities of AchE and ChAT in hippocampus in AD Rats. J Trad Chin Med Univ Hunan, 29 (3), 30-32.https://doi.org/10.3969/j.issn.1674-070X.2009.03.010

Zhai, P. P., Xu, L. H., Yang, J. J., Jiang, Z. L., Zhao, G. W., Sun, L., . . . Li, X. (2015). Reduction of inflammatory responses by L-serine treatment leads to neuroprotection in mice after traumatic brain injury.Neuropharmacology, 95 , 1-11.https://doi.org/10.1016/j.neuropharm.2015.02.026

Zhang, H. Y., Liang, Y. Q., Tang, X. C., He, X. C., \& Bai, D. L. (2002). Stereoselectivities of enantiomers of huperzine A in protection against beta-amyloid(25-35)-induced injury in PC12 and NG108-15 cells and cholinesterase inhibition in mice. Neurosci Lett, 317 (3), 143-146.https://doi.org/10.1016/s03043940(01)02437-5

Zhang, Z., Si, Y., Wu, H., Xu, H., \& Bai, L. (2005). Effects of Banxiaxiexin decoction and its diferent ingredient combinations on cholinergic neurons in rats with acute gastric ulcer. Chin J Basic Med Trad Chin Med, 11 (04), 283-284+287.https://doi.org/10.3969/j.issn.1006-3250.2005.04.016

Zhao, D., Li, X., Chen, S., Jing, W., Xing, J., Mu, J., \& Li, X. (2012). Effects of tenuigenin on learning, memory and expression of nicotinic acetylcholine receptor subunit alpha-7 in hippocampus in Alzheimer disease rats. Chin J Neuroimmun Neur, 19 (5), 349-353.https://doi.org/10.3969/j.issn.1006-2963.2012.05.008 
Zhao, H., Zhou, S., Zhang, M., Feng, J., Wang, S., Wang, D., . . . Wang, X. (2016). An in vitro AChE inhibition assay combined with UF-HPLC-ESI-Q-TOF/MS approach for screening and characterizing of AChE inhibitors from roots of Coptis chinensis Franch. J Pharm Biomed Anal, 120 , 235240.https://doi.org/10.1016/j.jpba.2015.12.025

Zhao, H. Y., Zhang, S. D., Zhang, K., Wang, X., Zhao, Q. Y., Zhang, S. J., . . . Huang, C. X. (2017). Effect of Shensong Yangxin on the Progression of Paroxysmal Atrial Fibrillation is Correlated with Regulation of Autonomic Nerve Activity. Chin Med J (Engl), 130 (2), 171-178.https://doi.org/10.4103/0366-6999.197997

Zhao, T., Li, D. J., Liu, C., Su, D. F., \& Shen, F. M. (2011). Beneficial effects of anisodamine in shock involved cholinergic anti-inflammatory pathway. Front Pharmacol, 2 , 23.https://doi.org/10.3389/fphar.2011.00023

Zhou, W., Wang, J., Li, Z., Li, J., \& Sang, M. (2016). MicroRNA-205-5b inhibits HMGB1 expression in LPS-induced sepsis. Int J Mol Med, 38 (1), 312-318.https://doi.org/10.3892/ijmm.2016.2613

Zhou, X., Wang, D., Li, F., Gong, D., Lu, F., \& Wang, K. (2015). Berberine hydrochloride improves insulin resistance by upregulating the xxpression of $\alpha 7$ nicotinic acetylcholine receptor. Act Med Univ Sci Tech Huazhong, 44 (5), 528-532.https://doi.org/10.3870/j.issn.1672-0741.2015.05.007

Zhu, R. L., Zhi, Y. K., Yi, L., Luo, J. F., Li, J., Bai, S. S., . . . Dong, Y. (2019). Sinomenine regulates CD14/TLR4, JAK2/STAT3 pathway and calcium signal via $\alpha 7 n A C h R$ to inhibit inflammation in LPS-stimulated macrophages. Immunopharmacol Immunotoxicol, 41 (1), 172177.https://doi.org/10.1080/08923973.2019.1568451

Zi, S. F., Li, J. H., Liu, L., Deng, C., Ao, X., Chen, D. D., \& Wu, S. Z. (2019). Dexmedetomidine-mediated protection against septic liver injury depends on TLR4/MyD88/NF- $\varkappa \mathrm{B}$ signaling downregulation partly via cholinergic anti-inflammatory mechanisms. Int Immunopharmacol, 76 , 105898.https://doi.org/10.1016/j.intimp.2019.105898

Figure legend

FIGURE 1 An analytical framework for the treatment of inflammatory diseases by CAP-based Chinese herbal medicine

\section{FIGURE 2 Regulation of cholinergic anti-inflammatory pathway}

(A) The brain contains the nicotinic acetylcholine receptor $\alpha 7$ ( $\alpha 7 \mathrm{nAChR})$ and muscarinic acetylcholine receptor (mAChR). Inflammatory cytokines are produced when the body stimulated by LPS and introduced into the nucleus tractus solitarius (NTS) of the brain via the vagus nerve. Brain integrates information and makes decisions, the vagus nerve activated reflexively and sends a signal to the spleen through splenic nerve.

(B) In spleen, norepinephrine (NE) releases and stimulates $\beta 2$ adrenergic receptors $(\beta 2 \mathrm{AR})$ in $\mathrm{T}$ cell to regulate the production of acetylcholine $(\mathrm{ACh})$, which is catalyzed by choline and acetyl coenzyme A through choline acetyltransferase (ChAT). ACh is transported into the vesicle by the vesicle acetylcholine transporter (vAChT) and secreted into the synaptic space.

(C) ACh binds to $\alpha 7 \mathrm{nAChR}$ on macrophages and $\alpha 7 \mathrm{nAChR}$ is activated, recruiting Janus kinase 2 (JAK2) to form a heterodimeric complex. Activating JAK2/signal transducer and activator of transcription 3 (STAT3) pathway, and phosphorylated STAT3 (p-STAT3) reduces nuclear translocation of nuclear factor kappa-B $(\mathrm{NF}-\varkappa \mathrm{B}, \mathrm{p} 50+\mathrm{p} 65)$, p-STAT3 forms a dimer and transfers to the nucleus, which prevents the production and release of proinflammatory cytokines. Followed by tyrosine phosphorylation of phosphatidylinositol kinase (PI3K) and phosphorylation of protein-serine-threonine kinase (Akt) to activate the PI3K/Akt pathway, which can reduce apoptosis and toll-like receptor 4 (TLR4) expression. Meanwhile, unphosphorylated STAT3 can also compete with inhibitor $\alpha$ of NF- $\chi \mathrm{B}(\mathrm{I} \varkappa \mathrm{B} \alpha)$ to bind NF- $\chi \mathrm{B}$ and inhibit TNF transcriptional activation. Activation of $\alpha 7 \mathrm{nAChR}$ can induce the production of miRNA, thereby inhibiting STAT3 mRNA translation. $\alpha 7 \mathrm{nAChR}$ activation can also directly inhibit the inhibitor of nuclear factor kappa-B kinase 
(IKK $\beta$ ) phosphorylation and affect NF- $x \mathrm{~B}$ pathway. In addition, $\alpha 7 \mathrm{nAChR}$ activation will down-regulate the mitogen-activated protein kinase (MAPK) pathway and affect inflammatory factors transcription. The activation of CAP downregulates the production of inflammatory factors such as tumor necrosis factor- $\alpha$ (TNF- $\alpha$ ), interleukin-6 (IL-6), interleukin-1 $\beta$ (IL-1 $\beta$ ), and high mobility group box 1 (HMGB1) to achieve the effect of controlling inflammation.

\section{FIGURE 3 Inflammatory diseases that can be treated through the cholinergic anti- inflammatory pathway}

The cholinergic anti-inflammatory pathway (CAP) is mainly related to brain, lung, cardiovascular, stomach, intestine, pancreas, joints, and other organs. Systemic inflammatory diseases and inflammatory diseases related to these organs can also be treated through CAP pathway. AD, Alzheimer's disease; ALI, Acute lung injury; AP, Acute pancreatitis; CIR, Cerebral ischemia reperfusion injury; MIR, Myocardial ischemia reperfusion injury; POI, Postoperative ileus; TBI, Traumatic brain injury; VD, Vascular dementia.

FIGURE 4 Therapeutic mechanism of Chinese herbal medicine on Alzheimer's disease through cholinergic pathway

In the cholinergic pathway related to Alzheimer's disease (AD), choline and acetyl-coenzyme A (AcCoA) are catalyzed by acetylcholine transferase (ChAT) to produce $\mathrm{ACh}$, which is transported to the synaptic cleft. The activity and content of acetylcholinesterase (AChE) directly affect the effect of ACh. The activation of $\alpha 7 \mathrm{nAChR}$ and mAChR increases the expression of amyloid precursor protein (APP) and reduces non$\beta$ amyloid peptides $(A \beta)$ by increasing $A \beta$ metabolism. In the early stage of $A D$, a low concentration of $A \beta$ activates hippocampal astrocytes to protect nerves, but in the middle and late stages, it accumulates too much to form a vicious circle, and a large amount of $A \beta$ is deposited in a feedback manner. $A \beta$ and $\alpha 7 \mathrm{nAChR}$ have high affinity and combine to form a complex, thereby blocking neurotransmitter transmission and signal transmission, causing nerve cell death. Both $\alpha 7 \mathrm{nAChR}$ activation and M1mAChR activation down-regulate Glycogen synthase kinase- $3 \beta$ (GSK-3 $\beta$ ) and reduce the hyperphosphorylation of tau protein, thereby reducing neurofibrillary tangles. Studies have found that Chinese herbal medicine increases the ACh level by increasing ChAT expression and inhibiting AChE. In addition, it activates $\alpha 7 \mathrm{nAChR}, \mathrm{M} 1 \mathrm{mAChR}$, and $\mathrm{M} 3 \mathrm{mAChR}$, inhibits neuroinflammation, reduces $\mathrm{A} \beta$ deposition, reduces nerve cell death, and reduces tau protein hyperphosphorylation, thereby achieving AD treatment.

\section{Hosted file}

Table.pdf available at https://authorea.com/users/369229/articles/488156-cholinergicanti-inflammatory-pathway-an-insight-into-inflammatory-diseases-treatment-with-chineseherbal-medicine

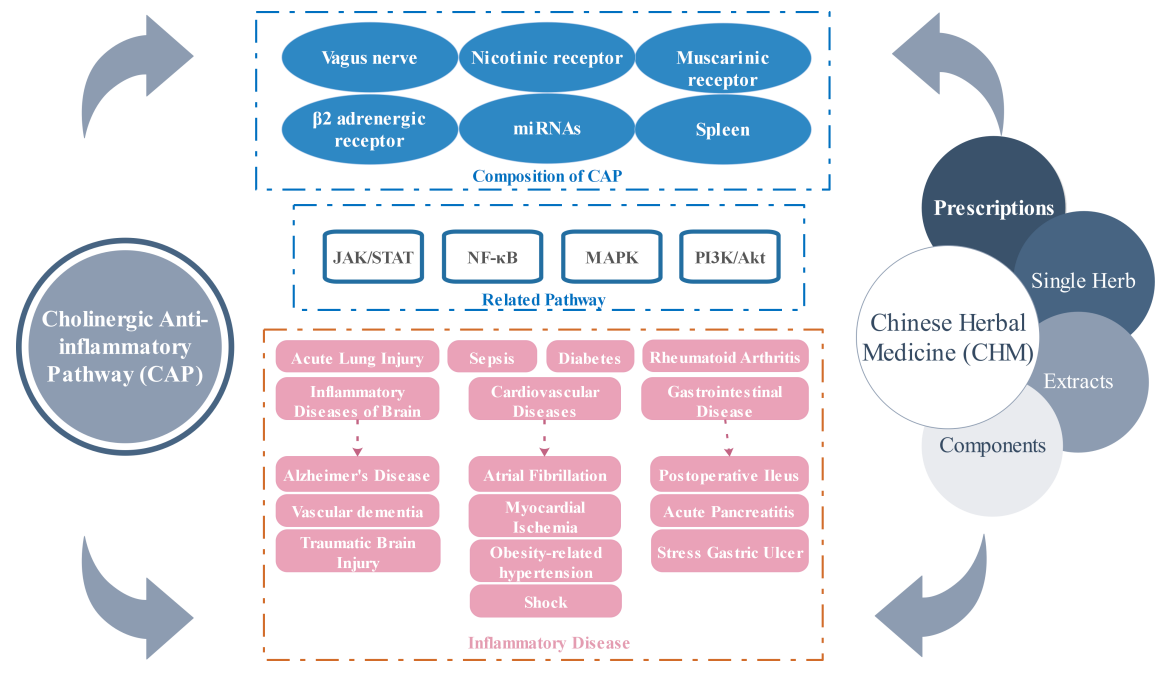



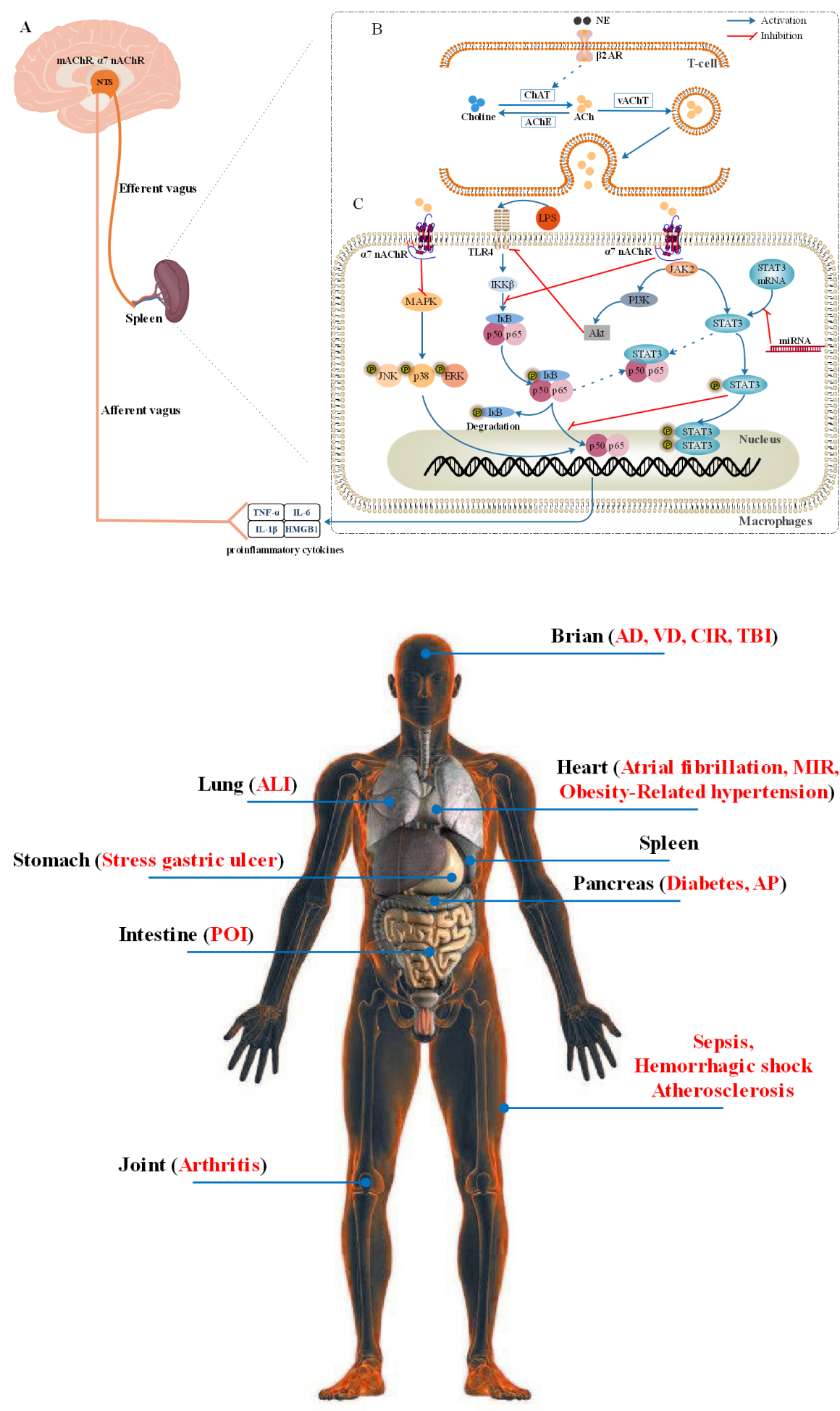


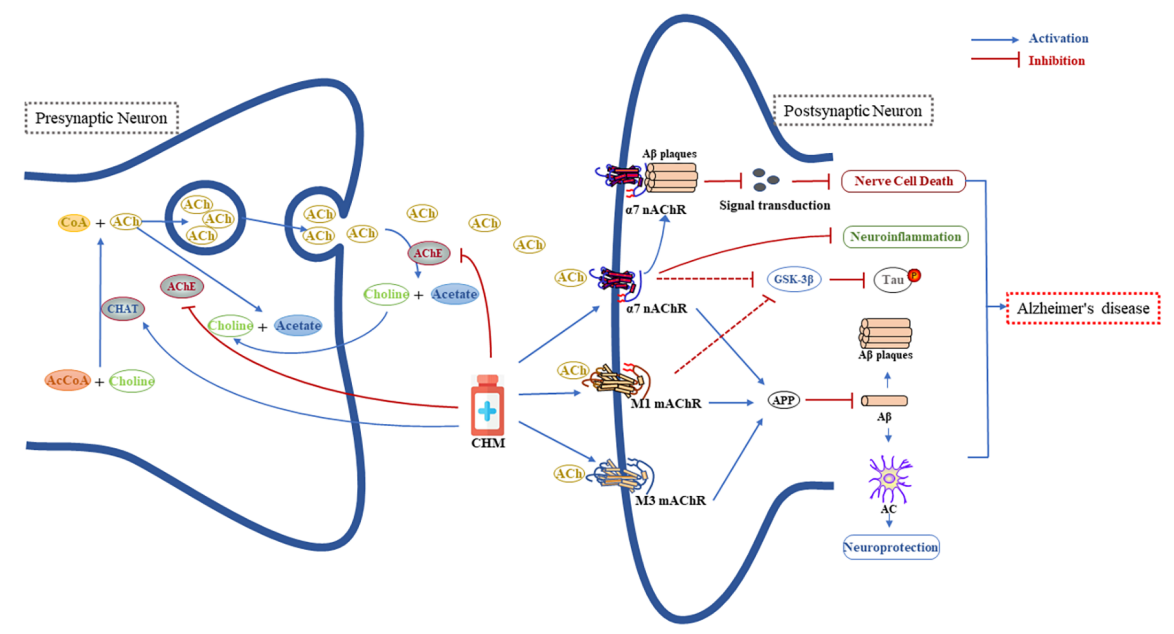

